\title{
1 senSCOPE: Modeling radiative transfer and biochemical processes in 2 mixed canopies combining green and senescent leaves with SCOPE
}

3 Javier Pacheco-Labrador ${ }^{1}$, Tarek S. El-Madany ${ }^{1}$, Christiaan van der Tol $^{2}$, M. Pilar Martin ${ }^{3}$, Rosario 4 Gonzalez-Cascon $^{4}$, Oscar Perez-Priego ${ }^{5}$, Jinhong Guan ${ }^{6}$, Gerardo Moreno ${ }^{7}$, Arnaud Carrara ${ }^{8}$, Markus 5 Reichstein $^{1}$ and Mirco Migliavacca ${ }^{1}$.

6 Max Planck Institute for Biogeochemistry, Hans Knöll Straße 10, Jena, D-07745, Germany

$7{ }^{2}$ Faculty of Geo-Information Science and Earth Observation (ITC), University of Twente, PO Box 217, AE 8 Enschede 7500, The Netherlands

9 Environmental Remote Sensing and Spectroscopy Laboratory (SpecLab), Institute of Economic, Geography and 10 Demography (IEGD-CCHS), Spanish National Research Council (CSIC), C/Albasanz 26-28, 28037 Madrid, 11 Spain

$12{ }^{4}$ Department of Environment, National Institute for Agriculture and Food Research and Technology (INIA), Ctra. 13 Coruña, Km. 7,5, 28040 Madrid, Spain

$14{ }^{5}$ Department of Biological Sciences Macquarie University, 6 Wally's Walk, NSW 2109, Australia.

$15{ }^{6}$ State Key Laboratory of Soil Erosion and Dryland Farming on the Loess Plateau, Northwest A\&F University, 16 Yangling, Shaanxi 712100, China

$17{ }^{6}$ Forest Research Group - INDEHESA University of Extremadura, 10600 Plasencia, Spain

$18{ }^{7}$ Fundación Centro de Estudios Ambientales del Mediterráneo (CEAM), Charles Darwin 14, Parc Tecnològic, 1946980 Paterna, Spain

20 Correspondence to: Javier Pacheco-Labrador (jpacheco@bgc-jena.mpg.de)

\section{Abstract.}

24 Semi-arid grasslands and other ecosystems combine green and senescent leaves featuring different

25 biochemical and optical properties, as well as functional traits. Knowing how these properties vary is

26 necessary to understand the functioning of these ecosystems. However, differences between green and 27 senescent leaves are not considered in recent models representing radiative transfer, heat, water and $28 \mathrm{CO}_{2}$ exchange such as the Soil-Canopy Observation of Photosynthesis and Energy fluxes (SCOPE).

29 Neglecting the contribution of senescent leaves to the optical and thermal signal of vegetation limits the 30 possibilities to use remote sensing information for studying these ecosystems; as well as neglecting their 

perpetuity. It is made available under aCC-BY 4.0 International license.

31 lack of photosynthetic activity increases uncertainty in the representation of ecosystem fluxes. In this

32 manuscript we present senSCOPE as a step towards a more realistic representation of mixed green and

33 senescent canopies. senSCOPE is a modified version of SCOPE model that describes a canopy

34 combining green and senescent leaves with different properties and function. The model relies on the same numerical solutions than SCOPE, but exploits the linear nature of the scattering coefficients to combine optical properties of both types of leaf. Photosynthesis and transpiration only take place in green leaves; and different green and senescent leaf temperatures are used to close the energy balance.

38 Radiative transfer of sun-induced fluorescence (SIF) and absorptance changes induced by the 39 xanthophyll cycle action are also simulated. senSCOPE is evaluated against SCOPE both using 40 synthetic simulations, forward simulations based on observations in a Mediterranean tree-grass 41 ecosystem, and inverting dataset of ground measurements of reflectance factors, SIF, thermal radiance 42 and gross primary production on a heterogeneous and partly senescent Mediterranean grassland. Results 43 show that senSCOPE outputs vary quite linearly with the fraction of green leaf area, whereas SCOPE 44 does not respond linearly to the effective leaf properties, calculated as the weighted average of green and senescent leaf parameters. Inversion results and pattern-oriented model evaluation show that senSCOPE improves the estimation of some parameters, especially chlorophyll content, with respect SCOPE retrievals during the dry season. Nonetheless, inaccurate knowledge of the optical properties of senescent matter still complicates model inversion. senSCOPE brings new opportunities for the

49 monitoring of canopies mixing green and senescent leaves, and for improving the characterization of the 50 optical properties of senescent material.

\section{Introduction}

52 Consistent monitoring of relevant vegetation properties is an essential step towards understanding the 53 response of vegetation function (e.g., photosynthesis, transpiration) to changes in environment. Among 54 others, photosynthetic performance and water use efficiencies are key elements to predict and 55 understand vegetation responses to the climate change scenarios (e.g., elevated atmospheric $\mathrm{CO}_{2}$ 56 concentration, higher temperatures and altered water regimes) (IPCC 2014). However, current Land 
bioRxiv preprint doi: https://doi.org/10.1101/2020.02.05.935064; this version posted February 6, 2020. The copyright holder for this preprint (which was not certified by peer review) is the author/funder, who has granted bioRxiv a license to display the preprint in perpetuity. It is made available under aCC-BY 4.0 International license.

57 Surface Models (LSM) predictions of these fluxes include large uncertainties (Friedlingstein et al.

58 2014); partly due to inadequate representation of different processes as well as to the lack of knowledge

59 of functional parameters describing plant function (e.g., maximum carboxylation rate $\left(V_{\text {cmax }}\right)$, maximum

60 electron transport rate $\left(J_{\max }\right)$ or the Ball-Berry stomatal sensitivity $(m)$ ) (Rogers 2014; Rogers et al.

61 2016; Schaefer et al. 2012). Recent efforts of the Remote Sensing (RS) community have focused on the

62 estimation of these parameters either using statistical approaches (Serbin et al. 2015; Silva-Perez et al.

63 2018), or combining Radiative Transfer Models (RTM) with Soil-Vegetation-Atmosphere Models

64 (SVAT) (Bayat et al. 2018; Camino et al. 2019; Dutta et al. 2019; Pacheco-Labrador et al. 2019; Zhang

65 et al. 2014; Zhang et al. 2018), notably using the Soil-Canopy Observation Photosynthesis and Energy

66 fluxes (SCOPE) model (van der Tol et al. 2009).

67 SCOPE represents radiative transfer of optical and thermal infrared radiation (TIR), in a homogeneous

68 1-D canopy, which is coupled with an energy balance and a photosynthesis models predicting heat and

69 water fluxes and carbon assimilation. SCOPE also propagates leaf level sun-induced chlorophyll

70 fluorescence (SIF) emission and absorptance changes related with the activation of the xanthophyll

71 cycle (Vilfan et al. 2018) to top of the canopy radiances. SCOPE uses Fluspect to model leaf optical

72 properties (Vilfan et al. 2016; Vilfan et al. 2018) and combines 4 different canopy RTM representing

73 outgoing radiation $\left(\mathrm{RTM}_{\mathrm{o}}\right)$, SIF $\left(\mathrm{RFM}_{\mathrm{f}}\right.$, (van der Tol et al. 2016)), TIR emission $\left(\mathrm{RTM}_{\mathrm{t}}\right)$ and

74 xanthophyll absorption $\left(\mathrm{RTM}_{\mathrm{z}}\right.$, (Vilfan et al. 2018)) that rely on the four stream SAIL extinction and

75 scattering coefficients model (Verhoef 1984). In addition, Yang and colleagues (2017) developed

76 mSCOPE, an extension of SCOPE that uses a different numerical solution of the radiative transfer

77 problem to represent 1-D but vertically heterogeneous canopies.

78 A current limitation of SCOPE is the lack of representation of within-canopy heterogeneity of

79 vegetation properties, and specifically the separation of green and senescent leaves, which feature large

80 differences in biophysical properties and function. When leaves senesce, flavonoids undergo enzymatic

81 oxidation processes within the leaf producing diverse semiquinones and quinones which can suffer non-

82 enzymatic secondary reactions with phenols, amino acids and proteins or other polyphenols (Pourcel et

83 al. 2007; Taranto et al. 2017). The result is a heterogeneous mixture of complex brown polymers, 

perpetuity. It is made available under aCC-BY 4.0 International license.

84 difficult to characterize in vivo and responsible of the yellow and brown tones that these leaves exhibit

85 (Guyot et al. 1996; Pourcel et al. 2007). The characterization of the optical properties of these

86 “senescent” or "brown” pigments of leaves were addressed by Jacquemoud (1988) using albino corn

87 leaves; however, the authors stated that the characterization had to be improved. In fact, the absorption

88 coefficients currently used by Prospect are usually attributed to F. Baret, via personal communication

89 (e.g., (Féret 2009)). Thus, the characterization of senescent pigments is not as thoroughly documented

90 as for other pigments (Feret et al. 2008; Féret et al. 2017; Jacquemoud and Baret 1990; Vilfan et al.

91 2018), and their concentration is presented in arbitrary units due to the measurement technique used in

92 their determination (Jacquemoud 1988). Also, when leaves further degrade their color changes (Kidnie

93 et al. 2015), and some of their optical properties might vary with respect to those characterized and used

94 by leaf-level RTM. For example, Melendo-Vega et al, (2018) suggested that overestimation of near

95 infrared reflectance factors in a semi-arid grassland could be related to senescent material, and that this

96 effect increased with its longevity.

97 Commonly used models such as PROSAIL (Jacquemoud et al. 2009), or more recently SCOPE, allocate

98 all the pigments in a unique "effective" according to the averaged concentrations of the different leaves

99 of the canopy. However, this approach does not adequately represent mixed canopies with varying

100 fractions of green and senescent leaves. The presence of non-photosynthetic elements in the canopy has

101 been already addressed in turbid medium RTM (Bach et al. 2001; Braswell et al. 1996; Wenhan 1993)

102 and used to improve the estimation of biophysical parameters such as leaf area index (LAI) or

103 chlorophyll concentration $\left(C_{\mathrm{ab}}\right)$ or the fraction of absorbed photosynthetically active radiation (Houborg 104 and Anderson 2009; Houborg et al. 2009; Houborg and McCabe 2016; Wenhan 1993). However, 105 senescent and green leaves do not only feature different optical properties, but also different 106 physiological processes. For example, senescent leaves present little or no chlorophyll content 107 (Hörtensteiner 2006; Whitfield and Rowan 1974) so that they do not assimilate $\mathrm{CO}_{2}$ through 108 photosynthesis. Also, senescent leaves do not transpire water and lack of stomatal regulation. Senescent 109 leaves can pose problems for the retrieval of biophysical variables if not adequately represented (Bacour 110 et al. 2002; Houborg and Boegh 2008; Wang et al. 2005). Analogously, inadequate representation of 
bioRxiv preprint doi: https://doi.org/10.1101/2020.02.05.935064; this version posted February 6, 2020. The copyright holder for this preprint (which was not certified by peer review) is the author/funder, who has granted bioRxiv a license to display the preprint in perpetuity. It is made available under aCC-BY 4.0 International license.

111 green and senescent leaf pools could also potentially induce uncertainties in the simulation of processes

112 at canopy scale related to photosynthesis and transpiration. Finally, given that SCOPE is now widely

113 used for retrieval of functional properties (Bayat et al. 2018; Camino et al. 2019; Dutta et al. 2019;

114 Pacheco-Labrador et al. 2019; Zhang et al. 2014; Zhang et al. 2018), these uncertainties can propagate

115 in the estimated parameters (Pacheco-Labrador et al. 2019). This fact may limit the application of recent

116 approaches combining RTM and SVAT models for the study of canopies or ecosystems featuring large

117 fractions of dry leaves (in particular in grasslands or semi-arid ecosystems) or for the monitoring of

118 vegetation health, crop productivity and phenology.

119 Senescent material is present in all vegetation, and for a remote sensing perspective is very critical for

120 annual plants such as grasslands (Houborg et al. 2009; Melendo-Vega et al. 2018), which cover about $12140 \%$ of the Earth's terrestrial surface (Anderson 2006). Grassland's phenology and function are strongly 122 governed by water availability, temperature, herbivory, fire, nitrogen deposition or $\mathrm{CO}_{2}$ concentration 123 increase (Anderson 2006; Cleland et al. 2006; Figueroa and Davy 1991; Luo et al. 2018; Migliavacca et 124 al. 2011; Richardson et al. 2013). Green plants transit to senescent, recently dead, and long-term dead 125 plants, each of them featuring different biophysical and optical properties (Kidnie et al. 2015). This 126 transition varies with meteorology (Ren and Zhang 2018), biophysical properties (Henry et al. 2008; 127 Sanaullah et al. 2010; Yuan and Chen 2009), plant functional types (Henry et al. 2008) and changes for 128 different parts of the plant (Henry et al. 2008; Koukoura et al. 2003). Usually, even in grasses, leaves 129 fall while stems stay longer and degrade more slowly due to differences in biochemical composition. 130 Therefore, in multi-species grasslands senescence and degradation can take place at different rates and 131 periods, increasing the variability of surface biophysical and optical properties as well as the complexity 132 of modeling and characterization. In fact, senescent material and litter are nowadays considered a 133 challenge for the estimation of biophysical properties in semi-arid grasslands (He and Mui 2010).

134 In this work, we present senSCOPE, a modified version of the SCOPE model that separates RTM and 135 physiological processes (photosynthesis and transpiration) for green and senescent leaves. senSCOPE 136 aims at improving the representation of radiative transfer and physiology in senescent canopies. The 137 model is then evaluated in three ways: 
bioRxiv preprint doi: https://doi.org/10.1101/2020.02.05.935064; this version posted February 6, 2020. The copyright holder for this preprint (which was not certified by peer review) is the author/funder, who has granted bioRxiv a license to display the preprint in perpetuity. It is made available under aCC-BY 4.0 International license.

1) We run a sensitivity analysis comparing forward simulations of SCOPE and senSCOPE under different meteorological conditions and under different combinations of vegetation parameters for different abundances of senescent leaves.

2) We use observations of model parameters and meteorological data at ecosystem scale to predict fluxes and compare them with EC data.

146 As in the former work, functional and biophysical model parameters are estimated by inverting SCOPE

3) We invert SCOPE and senSCOPE against the same dataset of ground observations of carbon against different combinations of the abovementioned variables sampled at plot scale in a Mediterranean grassland. New inversion boundaries are used according to observations of some of the parameters in the site. Results of both inversions are compared and evaluated using pattern-oriented model evaluation approach (Pacheco-Labrador et al. 2019).

\section{Description of senSCOPE}

152 The model senSCOPE extends the 1-D model SCOPE to describe homogeneous canopies combining 153 green and senescent leaves randomly mixed. Fig. 1 summarizes the conceptual differences between 154 SCOPE and senSCOPE. Green leaves contain chlorophylls and other photosynthetic pigments that 155 allow them to photosynthesize; and regulate their temperature via transpiration. In contrast, senescent 156 leaves only contain senescent pigments and neither photosynthesize nor transpire. These leaves present 157 some microbial activity related to its degradation, and superficial water (e.g., intercepted rainfall) can 158 evaporate from their surface; however these processes are not represented neither by SCOPE nor 159 senSCOPE. In senSCOPE, the leaf RTM Fluspect (Vilfan et al. 2016; Vilfan et al. 2018) simulates 160 reflectance, transmittance and, in the case of green leaves, also fluorescence according to the

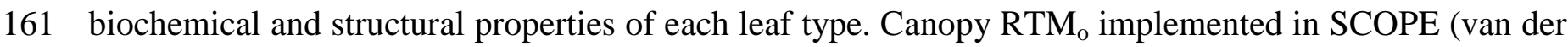
162 Tol et al. 2009) is modified to separately compute the radiation absorbed by each leaf type; and the 
nor transpire. Since green and senescent leaves feature different radiative balances, a modified $\mathrm{RTM}_{t}$ model quantifies thermal emission of each of these two leaf types separately and combines them according to the corresponding fractions of leaf area $(f)$; then the model calculates scattering and absorption of this diffuse flux. Eventually, fluorescence emission and optical changes induced by the activation of the xanthophyll cycle in the green leaves is propagated to top of canopy (TOC) radiances implemented in SCOPE. Both models are coded in Matlab (Matwoks Inc., Natick, MA, USA).

\section{SCOPE} xanthophyll cycle $\left(\Delta L_{\mathrm{x}, \lambda}\right)$

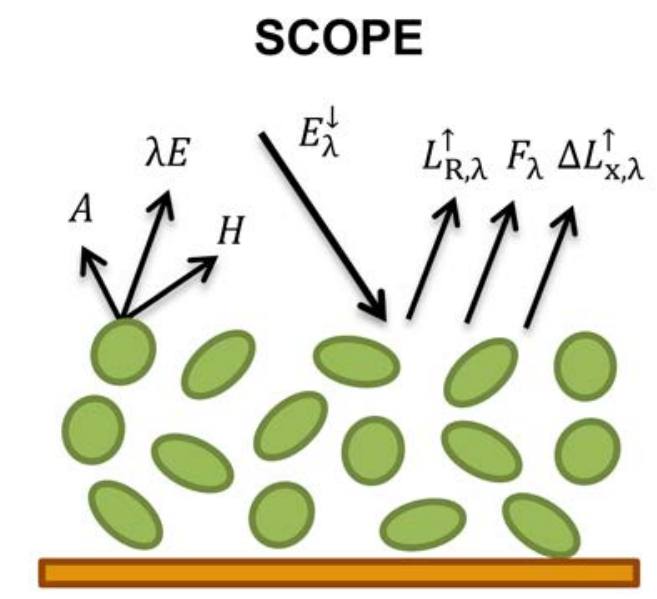

\section{senSCOPE}

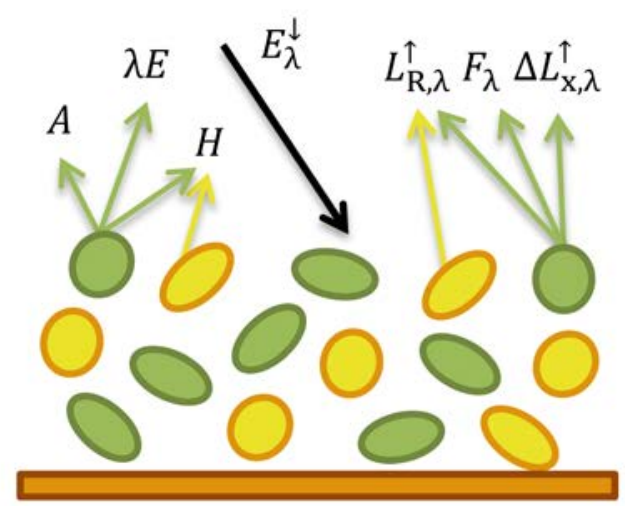

Figure 1. Conceptual differences between SCOPE and senSCOPE models. Green and yellow colours correspond to green and senescent leaves, respectively. Black arrows show processes featured by all leaves; whereas coloured arrows refer to processes featured only for a given type of leaf. The scheme represents assimilation $(A)$, latent $(\lambda E)$ and sensible heat $(H)$ fluxes, incoming spectral irradiance $\left(E_{\lambda}\right)$, reflected spectral radiance $\left(L_{\mathrm{R}, \lambda}\right)$, emitted fluorescence radiance $\left(F_{\lambda}\right)$ and changes in $L_{\mathrm{R}, \lambda}$ due to activation of

senSCOPE relies on the same solution of the radiative transfer problem implemented in SCOPE, since it exploits the linear nature of the single leaf scattering efficiency factors (Verhoef 1984) to combine the optical properties of green and senescent leaves in an "averaged" leaf. This is simple if leaf angle distribution is assumed the same for both types of leaves. The main advantage of this approach is that it allows representing physiological processes separately in each leaf type. This is important since photosynthesis and transpiration are non-linearly related with radiation and leaf temperature, and 
184 therefore might not be adequately represented by a model featuring a unique leaf type characterized by

185 the “averaged parameters” of photosynthetic and non-photosynthetic leaves.

186 senSCOPE requires a larger number of parameters than SCOPE, since two different leaves must be 187 described, as well as their respective area fractions. Alternatives to minimize the number of parameters 188 and simplify the application of the model in inverse problems are presented in Sect. 3.2.2 and discussed 189 later.

\section{$190 \quad$ 2.1 Radiation Fluxes}

191 As SCOPE, senSCOPE relies on SAIL 4-stream theory that can be summarized by a system of four 192 linear equations describing the radiative transfer of the solar direct flux $\left(E_{\mathrm{s}}\right)$, the downward diffuse flux $193\left(E^{-}\right)$, the upward diffuse flux $\left(E^{+}\right)$, and the flux in the observation direction $\left(E_{0}\right)$.

$194 \frac{d E_{\mathrm{s}}}{L d x}=k E_{\mathrm{s}}$,

$\frac{d E^{-}}{L d x}=-s E_{\mathrm{S}}+a E^{-}-\sigma E^{+}$,

$\frac{d E^{+}}{L d x}=-s^{\prime} E_{\mathrm{s}}+\sigma E^{-}-a E^{+}$,

$\frac{d E_{\mathrm{o}}}{L d x}=w E_{\mathrm{s}}+v E^{-}+v^{\prime} E^{+}-K E_{\mathrm{o}}$,

198 In this system, $x$ represents the vertical relative height within the canopy ( $x=0$ for top, $x=-1$ for 199 bottom), and $L$ represents the Leaf Area Index (also $L A I$ ). The remaining variables are the SAIL 200 coefficients defined for first time by Verhoef (1984). $k$ and $K$ are the extinction coefficients in the solar 201 and observation directions, respectively. They depend on the sun-view geometry, $L A I$ and the leaf angle 202 distribution $(L A D)$; and they are therefore independent of leaf optical properties. $s, a, \sigma, s^{\prime}, w, v$ and $v^{\prime}$ 203 are the scattering coefficients depending on sun-view geometry, canopy structure and leaf optical 204 properties. These coefficients define the relationship between a given incident flux $\left(E_{1}\right)$ and a given 205 scattered flux $\left(E_{2}\right)$ in the canopy, and they are computed by integrating single-leaf scattering efficiency 206 factors $\left(Q_{\mathrm{sc}}\right)$ that represent the analogous relationship for individual leaves. The scattering coefficient 
bioRxiv preprint doi: https://doi.org/10.1101/2020.02.05.935064; this version posted February 6, 2020. The copyright holder for this preprint (which was not certified by peer review) is the author/funder, who has granted bioRxiv a license to display the preprint in perpetuity. It is made available under aCC-BY 4.0 International license.

207 (b) corresponding to all the leaves of given zenith inclination angle $\left(\theta_{\mathrm{l}}\right)$ can be defined as (Verhoef 208 1984):

$b\left(\theta_{1}\right)=\frac{L^{\prime}}{2 \pi} \int_{0}^{2 \pi} Q_{\mathrm{sc}}\left(E_{1}, E_{2}\right) d \varphi_{\mathrm{l}}$

210 where $L^{\prime}$ is the $L A I$ contained in a horizontal layer of the canopy of width $d x$ and $\varphi_{1}$ is the leaf azimuth 211 angle.

212 As in SCOPE, senSCOPE solves the radiative transfer problem numerically, defining a discrete number

213 of canopy layers and leaf angles. $Q_{\mathrm{sc}}\left(E_{1}, E_{2}\right)$ are defined assuming that individual leaves are Lambertian

214 diffusors of known hemispherical reflectance $(\rho)$ as and hemispherical transmittance $(\tau)$. $\rho$ and $\tau$ are

215 predicted in SCOPE by Fluspect (Vilfan et al. 2016). For each pair of incident and scattered fluxes, $216 Q_{\mathrm{sc}}\left(E_{1}, E_{2}\right)$ is defined as a linear combination of $\rho$ and/or $\tau$ weighted by spectrally invariant factors 217 determined by the geometry of the leaf, or more specifically, the projection of the leaves with respect to 218 the incident flux $\left(E_{1}\right)$ and the downward $(-)$ or upward $(+)$ scattered flux $\left(E_{2}\right)$. As proposed by Bach et 219 al, (2001), senSCOPE exploits this linear nature of $Q_{\text {sc }}$ to combine the $\rho$ and the $\tau$ of green and 220 senescent leaves into an averaged factors; weighted by their corresponding fractions of leaf area (Eq. 3 221 and 4). This approach allows applying the solution already proposed by van der Tol et al., (2009) for the 222 linear system shown in Eq. 1a-d.

$223 \rho=f_{\text {green }} \rho_{\text {green }}+\left(1-f_{\text {green }}\right) \rho_{\text {senes }}$,

$224 \tau=f_{\text {green }} \tau_{\text {green }}+\left(1-f_{\text {green }}\right) \tau_{\text {senes }}$,

225 where subscripts "green” and “senes” indicate the type of leaf. Notice that the weighted average of $\rho$ 226 and $\tau$ is not equivalent to the factors predicted for a weighted average of the leaf parameters.

227 This approach is suitable to represent the radiative transfer of a canopy of homogeneously mixed green 228 and senescent leaves. In order to represent physiological processes for each leaf type separately, it is 229 necessary differentiating the amount total radiation absorbed by each leaf type, and the 230 photosynthetically active radiation $(P A R)$ absorbed by chlorophyll ( $\left.E_{\text {ap,Chl }}\right)$. SCOPE quantifies $E_{\text {ap,Cab }}$ $231\left(\mathrm{~W} \mathrm{~m}^{-2}\right)$ using the relative absorption of this pigment respect to the remaining total absorption in the leaf 

perpetuity. It is made available under aCC-BY 4.0 International license.

232 in each spectral band $\left(k_{\mathrm{Chl}, \mathrm{rel}}\right)$. $E_{\mathrm{ap}, \mathrm{Chl}}$ is computed for the direct $\left(E_{\mathrm{ap}, \mathrm{Chl,dir}}\right)$ and the diffuse irradiances

233 ( $\left.E_{\text {ap,Chl,dif }}\right)$ as follows:

$234 E_{\text {ap,Chl,dir }}=f_{\text {green }} \int_{\lambda=400}^{\lambda=700} k_{\text {Chl,rel,green }}(\lambda) E_{\text {sun }}(\lambda)\left[1-\rho_{\text {green }}(\lambda)-\tau_{\text {green }}(\lambda)\right] d \lambda$,

$235 E_{\mathrm{ap}, \mathrm{Chl}, \mathrm{dif}}(x)=f_{\text {green }} \int_{\lambda=400}^{\lambda=700} k_{\mathrm{Chl} \text {,rel,green }}(\lambda)\left[E^{-}(x, \lambda)+E^{+}(x, \lambda)\right]\left[1-\rho_{\text {green }}(\lambda)-\tau_{\text {green }}(\lambda)\right] d \lambda$,

236 where $\lambda$ is the wavelength and $k_{\mathrm{Chl,rel}, \text { green }}$ is $k_{\mathrm{Chl}, \text { rel }}$ in the green leaves. These quantities are calculated 237 from the upward and downward fluxes without modifying the transfer of radiation. Since senSCOPE 238 defines senescent leaves as containing no chlorophyll, $k_{\mathrm{Chl}, \mathrm{rel}}=0$ in senescent leaves and for this reason, 239 absorbed PAR used to simulate photosynthesis in sunlit $\left(E_{\mathrm{ap}, \mathrm{Chl}, \mathrm{u}}\right)$ and shaded leaves $\left(E_{\mathrm{ap}, \mathrm{Chl}, \mathrm{h}}\right)$ per total

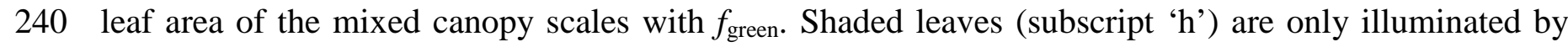
241 diffuse light (Eq. 7); whereas Eq. 5 and 6 must be combined to get $E_{\text {ap,Chl }}$ in the sunlit leaves $\left(E_{\text {ap,Chl,u }}\right.$, 242 subscript 'u') (Eq. 8).

$E_{\mathrm{ap}, \mathrm{Chl}, \mathrm{h}}(x)=E_{\mathrm{ap}, \mathrm{Chl}, \mathrm{dif}}(x)$,

$244 E_{\mathrm{ap}, \mathrm{Chl}, \mathrm{u}}\left(x, \theta_{\mathrm{l}}, \varphi_{\mathrm{l}}\right)=\left|f_{\mathrm{s}}\left(x, \theta_{\mathrm{l}}, \varphi_{\mathrm{l}}\right)\right| E_{\mathrm{ap}, \mathrm{Chl}, \mathrm{dir}}+E_{\mathrm{ap}, \mathrm{Chl}, \mathrm{dif}}(x)$,

245 where $f_{\mathrm{s}}$ is a geometric factor accounting for the projection of each leaf towards the sun.

246 Total absorbed radiation is used to compute the radiation budget in the canopy and determines leaf 247 temperature, which has implications for photosynthesis and transpiration, and must therefore be 248 computed separately for each leaf type. Total absorbed radiation is computed by SCOPE similarly as in 249 Eq. 5-8, but integrating the fluxes in the full spectral domain (e.g., 400-50.000 nm):

$250 E_{\mathrm{a}, i, \mathrm{dir}}=f_{\mathrm{i}} \int_{\lambda=400}^{\lambda=50000} E_{\mathrm{sun}}(\lambda)\left[1-\rho_{i}(\lambda)-\tau_{i}(\lambda)\right] d \lambda$,

$251 E_{\mathrm{a}, i, \operatorname{dif}}(x)=f_{\mathrm{i}} \int_{\lambda=400}^{\lambda=50000}\left[E^{-}(x, \lambda)+E^{+}(x, \lambda)\right]\left[1-\rho_{\mathrm{i}}(\lambda)-\tau_{\mathrm{i}}(\lambda)\right] d \lambda$,

$252 E_{\mathrm{a}, i, \mathrm{~h}}(x)=E_{\mathrm{a}, i, \operatorname{dif}}(x)$

$E_{\mathrm{a}, i, \mathrm{u}}\left(x, \theta_{\mathrm{l}}, \varphi_{\mathrm{l}}\right)=\left|f_{\mathrm{s}}\left(x, \theta_{\mathrm{l}}, \varphi_{\mathrm{l}}\right)\right| E_{\mathrm{a}, i, \mathrm{dir}}+E_{\mathrm{a}, i, \mathrm{dif}}(x)$,

254 Where subscript “i” now stands for either 'green’ or 'senescent'. 
256 As in SCOPE, energy balance is closed iteratively by modifying canopy and soil temperatures until the

257 following is met for the soil and for all leaf angles and layers separately:

$258\left|R_{\mathrm{n}}-H-\lambda E-G\right|<\varepsilon_{\text {threshold }}$

259 where $R_{\mathrm{n}}$ is net radiation, $H$ is latent heat flux, $\lambda E$ is energy heat flux, $G$ is soil heat flux and $\varepsilon_{\text {treshold }}$ is a 260 predefined threshold for the accepted energy balance closure error ( $\varepsilon_{\text {treshold }}$ ), all in $\mathrm{W} \mathrm{m}^{-2}$.

261 senSCOPE addresses the energy balance separating the processes occurring in green and senescent 262 leaves, where only the first are assumed to photosynthesize and transpire. Therefore, $\varepsilon_{\text {ebal }}$ is separated 263 into the following elements (Eq. 14):

$R_{\mathrm{n}, \text { green }}-R_{\mathrm{n}, \text { senes }}-R_{\mathrm{n} \text {,soil }}-H_{\text {green }}-H_{\text {senes }}-H_{\text {soil }}-\lambda E_{\text {green }}-\lambda E_{\text {soil }}-G=\varepsilon_{\text {ebal }}$,

265 where the subscript "soil" refers to soil fluxes, and only green leaves and soil contribute to $\lambda E$. 266 However, notice that similarly as in SCOPE, the energy balance is separately closed for soil and for all 267 leaf angles, layers and leaf types.

268 In order to compute $R_{\mathrm{n}}$, the contribution of thermal emission must be added to the absorbed radiation 269 calculated in Sect. 2.1. senSCOPE separately represents the temperatures of green and senescent leaves $270\left(T_{\mathrm{c}, \text { green }}, T_{\mathrm{c}, \text { senes}}\right.$, respectively) since they absorb radiation cool down differently. Distinguishing these 271 temperatures has an impact on the calculation of photosynthesis, which is temperature dependent. 272 Consequently, black-body thermal emission $\left(H_{\mathrm{c}}\right)$ is different for each leaf type $\left(H_{\mathrm{c}, \text { green, }} H_{\mathrm{c}, \text { senes }}\right)$; and the 273 on-sided black-body thermal emission of all leaves is computed as a linear combination of the emission 274 of each leaf type in the canopy:

$275 \varepsilon H_{\mathrm{c}}=f_{\text {green }} \varepsilon_{\text {green }} H_{\mathrm{c} \text {,green }}\left(T_{\mathrm{c}, \text { green }}\right)+\left(1-f_{\text {green }}\right) \varepsilon_{\text {senes }} H_{\mathrm{c}, \text { senes }}\left(T_{\mathrm{c}, \text { senes }}\right)$,

276 where $\varepsilon$ is the emissivity, and equals absorptance $(1-\rho-\tau)$ according to Kirchhoff's Law. The propagation 277 of emitted radiation by leaves and soil through the canopy is calculated using the averaged layer 278 properties as in the original SCOPE. In order to quantify the net thermal radiation (emitted minus 
absorbed) $\left(R_{n, t}\right)$ senSCOPE calculates the amount of energy absorbed by each leaf type using their

$281 R_{n, \text { t,green }}=\left[E^{-}+E^{+}-2 H_{\text {green }}\right] \varepsilon_{\text {green }} f_{\text {green }}$,

282

$R_{n, \mathrm{t}, \text { senes }}=\left[E^{-}+E^{+}-2 H_{\text {senes }}\right] \varepsilon_{\text {senes }}\left(1-f_{\text {green }}\right)$,

283 where and $E^{-}$and $E^{+}$are the diffuse emitted fluxes. $R_{n, t}$ of sunlit and shaded leaves is computed 284 separately. These are energy fluxes per total (senescent plus green) leaf surface area. Therefore, canopy 285 net radiation is computed as the addition of $E_{\mathrm{a}}$ and $R_{n, \mathrm{t}}$; and $R_{n, \mathrm{t}}=R_{n, \mathrm{t}, \text { green }}+R_{n, \mathrm{t}, \text { senes }}$ without the need to 286 further weight by fraction.

287 Aerodynamic resistances are computed as in SCOPE for the whole mixed canopy, since they depend on 288 meteorology and canopy structure. Consequently water and heat fluxes $\left(H_{\text {green }}, H_{\text {senes }}\right.$ and $\left.\lambda E_{\text {green }}\right)$ in 289 senSCOPE are computed with an identical representation of resistances as in SCOPE, but with leaf 290 temperatures differentiated per leaf type. These fluxes are defined per unit of leaf-type surface, and need 291 to be scaled to the fraction of $L A I$ represented by each leaf type in the mixed canopy. Eventually, 292 senSCOPE iteratively resolves six temperatures: sunlit and shaded green leaves $\left(T_{\mathrm{c}, \mathrm{u}, \text { green, }}, T_{\mathrm{c}, \mathrm{h}, \mathrm{senes}}\right)$, 293 sunlit and shaded senescent leaves ( $\left.T_{\mathrm{c}, \mathrm{u}, \mathrm{senes}}, T_{\mathrm{c}, \mathrm{h}, \mathrm{s} s e n e s}\right)$, and both sunlit and shaded soil $\left(T_{\mathrm{s}, \mathrm{u}}, T_{\mathrm{s}, \mathrm{h}}\right)$.

\subsection{Photosynthesis}

295 In senSCOPE, only green leaves photosynthesize and transpire. Photosynthesis is driven by the PAR absorbed by chlorophyll ( $A P A R_{\text {Chl; }}$ which equals $E_{\text {ap,Chl }}$ transformed from $\mathrm{W} \mathrm{m}^{-2}$ to $\mu \mathrm{mol} \mathrm{m}^{-2} \mathrm{~s}^{-1}$ ). The absorbed PAR by chlorophyll in green leaves per unit green leaf area is $E_{\mathrm{ap}, \mathrm{Chl}, \text { green }}=E_{\mathrm{ap}, \mathrm{Chl}} / f_{\text {green. }}$. Other area-based inputs such as maximum carboxylation rate $V_{\mathrm{cmax}}\left[\mu \mathrm{mol} \mathrm{m} \mathrm{s}^{-2} \mathrm{~s}^{-1}\right.$, as well as model outputs

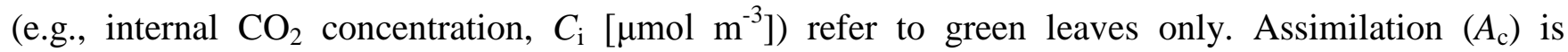
300 therefore initially computed per unit green leaf area. The stomatal conductance $\left(r_{\mathrm{cw}}\right)$ as output of the 301 leaf biochemical model is further used to calculate the transpiration of green leaves $\lambda E_{\text {green }}$, also per unit 302 green leaf area. Consequently, both fluxes first calculated per unit green leaf area, and later scaled with 303 $f_{\text {green }}$. 
305 SCOPE computes leaf level fluorescence emission using three main elements: incident irradiance in the

306 excitation range $400-750 \mathrm{~nm}$, excitation-fluorescence (E-F) matrices $\left(M\left(\lambda_{\mathrm{e}}, \lambda_{\mathrm{f}}\right)\right.$ and $M^{\prime}\left(\lambda_{\mathrm{e}}, \lambda_{\mathrm{f}}\right)$ for

307 backwards and forward fluorescence, respectively), and the amplification factors $\Phi_{f}$, which are

308 provided by the biochemical model for sunlit and shaded leaves. E-F matrices represent the excitation

309 of chlorophyll and the radiative transfer of incident and re-emitted radiation inside the leaf (Vilfan et al.

310 2016). In senSCOPE the leaf fluorescence emission is only calculated for green leaves, because for

311 senescent leaves, the E-F matrices equal zero. Then the emission is scaled with $f_{\text {green }}$.

$312 E_{\mathrm{l}}^{f}=f_{\text {green }} \cdot \Phi_{f}^{\prime} \cdot\left[\left(M_{\text {green }}^{\prime}\left(\lambda_{e}, \lambda_{f}\right)+M_{\text {green }}^{\prime}\left(\lambda_{e}, \lambda_{f}\right)\right)\right] \otimes E$,

313 Leaf level fluorescence emission is then propagated to top of the canopy combining the same radiative

314 transfer approach used by SCOPE and the averaged leaf optical properties ( $\rho$ and $\tau$ ) for the mixed

315 canopy.

\subsection{Xanthophyll cycle}

317 A recent version of SCOPE incorporates Fluspect-CX (Vilfan et al. 2018), a leaf RTM that simulates

318 the variations in leaf optical properties induced by the activation of the xanthophyll cycle for 319 photosynthetic down-regulation-, and propagates these variations from leaf to canopy level radiances.

320 Changes in leaf optical properties are computed after photosynthesis, as a function of the rate 321 coefficient for non-photochemical quenching $\left(K_{n}\right)$ provided by the biochemical module. This rate serves 322 as a scaling factor of leaf $\rho$ and $\tau$ between two extreme cases of with completely activated and 323 completely deactivated xanthophyll cycle. In senSCOPE, senescent leaves show no carotenoids, no 324 xanthophyll cycle and no related changes in optical properties; for this reason, the extreme cases 325 calculated on the averaged $\rho$ and $\tau$ simulate only variations induced by the green leaves. $K_{\mathrm{n}}$ is a rate 326 defining the probability of the different fates of photons exciting chlorophyll, therefore, and similarly to $327 \Phi_{f}$, it does not require additional correction. Therefore, senSCOPE uses the same radiative transfer 328 functions than SCOPE for the propagation of signals related with the xanthophyll cycle. 
bioRxiv preprint doi: https://doi.org/10.1101/2020.02.05.935064; this version posted February 6, 2020. The copyright holder for this preprint (which was not certified by peer review) is the author/funder, who has granted bioRxiv a license to display the preprint in

3. Methods perpetuity. It is made available under aCC-BY 4.0 International license.

\section{0}

\subsection{Comparison with SCOPE model. Sensitivity analysis}

331 In order to evaluate the differences between senSCOPE and the original model SCOPE (van der Tol et

332 al. 2009), we run two different series of forward simulations modifying separately meteorological

333 variables $\left(\mathrm{F}_{\text {meteo }}\right)$ and vegetation properties $\left(\mathrm{F}_{\mathrm{veg}}\right)$. Eleven different canopies with $f_{\text {green }}$ ranging between

3340.0 and 1.0 with steps of 0.1 were simulated. As input to SCOPE we used weighted averages of the leaf

335 parameters of each leaf type; similarly as field leaf measurements would be averaged to calculate

336 canopy mean values.

337 In order to provide realistic meteorological forcing in the simulations $F_{\text {meteo, we used actual }}$ 338 measurements acquired in the research site of Majadas de Tiétar between $5^{\text {th }}$ and the $20^{\text {th }}$ May 2016 339 (day of the year (DoY) 126 and 141, respectively). Fig. 2 summarizes this dataset.

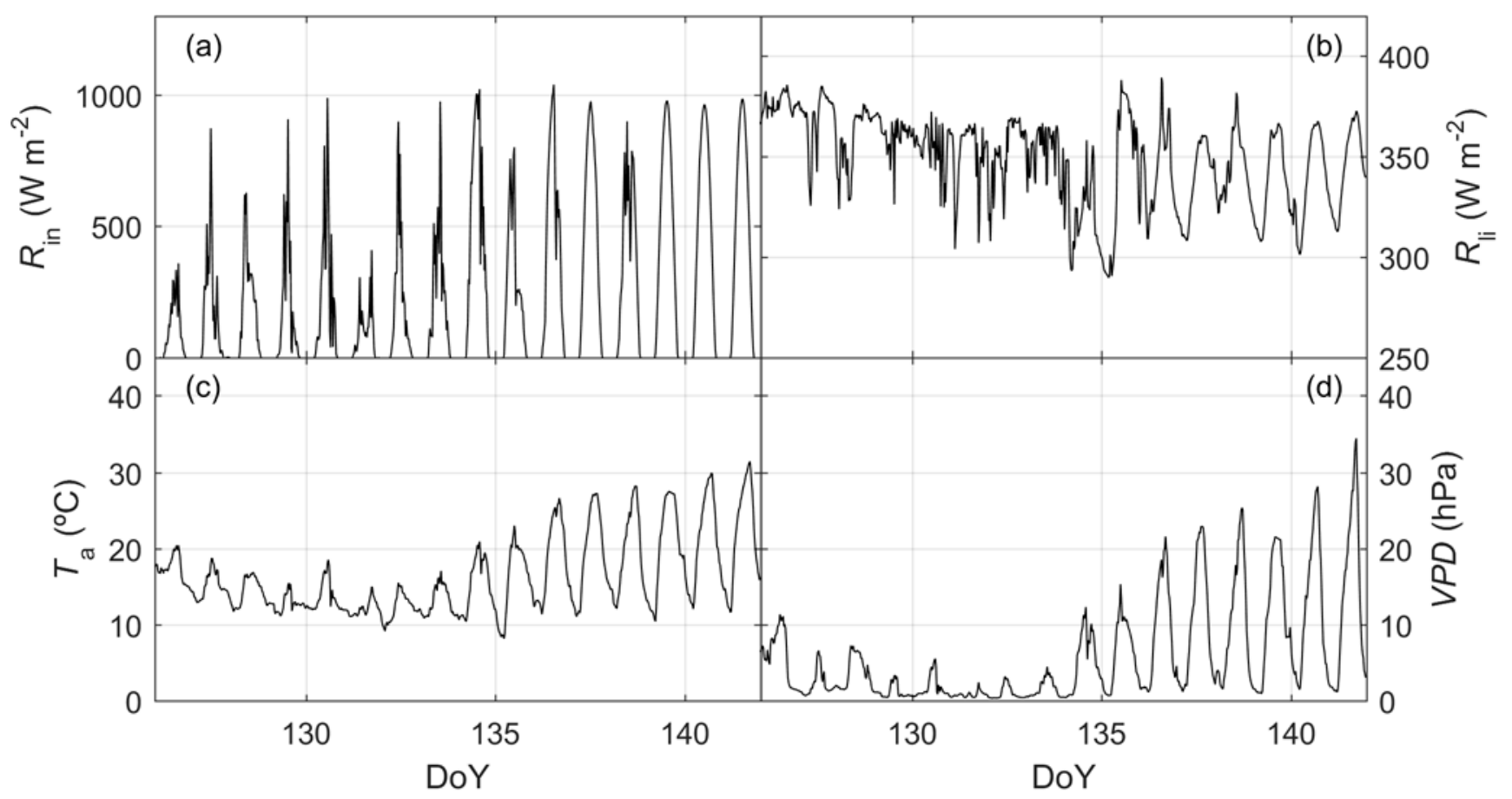


bioRxiv preprint doi: https://doi.org/10.1101/2020.02.05.935064; this version posted February 6, 2020. The copyright holder for this preprint (which was not certified by peer review) is the author/funder, who has granted bioRxiv a license to display the preprint in perpetuity. It is made available under aCC-BY 4.0 International license.

341 Figure 2. Short wave (a) and long wave incoming radiation (b), air temperature (c) and vapour pressure

deficit (d) recorded in Majadas de Tiétar between the $5^{\text {th }}$ and the $20^{\text {th }}$ May 2019 (DoY 126 and 141, respectively) used in the forward simulation $F_{\text {meteo }}$.

344 Short wave incoming radiation $\left(R_{\mathrm{in}}, \mathrm{W} \mathrm{m}{ }^{-2}\right)$, long wave incoming radiation $\left(R_{\mathrm{li}}, \mathrm{W} \mathrm{m}^{-2}\right)$, air temperature $345\left(T_{\mathrm{a}},{ }^{\circ} \mathrm{C}\right)$, atmospheric vapour pressure $\left(e_{\mathrm{a}}, \mathrm{hPa}\right)$, wind speed $\left(u, \mathrm{~m} \mathrm{~s}^{-1}\right)$, air pressure $(p$, hPa) and soil 346 moisture ( $S M_{\mathrm{p}}$, \% volume) were provided by a sub-canopy eddy covariance station at $1.6 \mathrm{~m}$ height 347 (detailed description of the system can be found in El-Madany et al, (2018) and Perez-Priego et al, 348 (2017)). Vapour pressure deficit (VPD, hPa) was calculated from $T_{\mathrm{a}}$ and $e_{\mathrm{a}}$; also, soil resistance for 349 evaporation from the pore space $\left(r_{\mathrm{ss}}, \mathrm{s} \mathrm{m}^{-1}\right)$ was estimated as a function of using $S M_{\mathrm{p}}$ the model SCOPE 350 v1.73. Sun zenith $\left(\theta_{\mathrm{s}}\right)$ and azimuth $\left(\varphi_{\mathrm{s}}\right)$ angles were computed from timestamps and site location. In the $351 \mathrm{~F}_{\text {meteo }}$ runs, only the abovementioned variables were modified; leaf and canopy properties were kept 352 constant for the different $f_{\text {green }}$ levels tested. Only daytime data $\left(\theta_{\mathrm{s}}<85.0 \mathrm{deg}\right)$ were used in the 353 simulation; which equals 422 runs per model and $f_{\text {green }}$ level.

$354 \mathrm{~F}_{\text {veg }}$ represented varying vegetation properties under constant meteorological conditions. To do so, we 355 selected midday conditions of the $18^{\text {th }}$ May 2019 (DoY 139). A look up table with 500 samples of $C_{\text {ab }}$, 356 carotenoids concentration $\left(C_{\mathrm{ca}}\right), V_{\mathrm{cmax}}$, Fluorescence quantum efficiency $\left(f_{\mathrm{qe}}\right), m$ and $L A I$ was generated 357 using Latin Hypercube Sampling (McKay et al. 1979). $C_{\mathrm{ca}}$ and $V_{\mathrm{cmax}}$ were constrained as a function of $358 C_{\mathrm{ab}}$ mimicking the relationships (linear function and noise) reported in Sims and Gamon (2002) and 359 Croft et al, (2017), respectively. Table 1 shows the ranges of variation generated for each parameter 360 varying in each $\mathrm{F}_{\text {veg }}$ simulation. Additionally, a smaller dataset was generated modifying only $L A I$ or $361 C_{\mathrm{ab}}$ (and $V_{\mathrm{cmax}}$ and $C_{\mathrm{ca}}$ as a function of these) to illustrate an example of the response of models to these 362 parameters. Several model outputs and internal parameters were evaluated. Moreover, we also 363 compared the predicted underlying water use efficiency ( $u W U E$, Eq. 19):

$364 u W U E=\frac{A}{\lambda E_{\mathrm{c}}} \sqrt{V P D}$,

365 where $\lambda E_{\mathrm{c}}$ is the canopy $\lambda E$, excluding evaporation from the soil. 
368 Table 1. Vegetation parameters used in the forward simulation $\mathbf{F}_{\text {veg. }}$

\begin{tabular}{|l|l|l|l|}
\hline Parameter & Symbol & Units & Range \\
\hline Leaf chlorophyll content & $C_{\mathrm{ab}}$ & $\mu \mathrm{g} \mathrm{cm}^{-2}$ & {$[0.13,99.98]$} \\
\hline Leaf carotenoids content & $C_{\mathrm{ca}}$ & $\mu \mathrm{g} \mathrm{cm}^{-2}$ & {$[0.02,37.26]$} \\
\hline Maximum carboxylation capacity & $V_{\mathrm{cmax}}$ & $\mathrm{mmol} \mathrm{m}^{-2} \mathrm{~s}^{-}$ & $[0.40,162.78]]$ \\
\hline Ball-Berry sensitivity parameter & $\mathrm{m}$ & - & \\
\hline Fluorescence quantum efficiency & $f_{\mathrm{qe}}$ & - & {$[0.05,39.98]$} \\
\hline Leaf area index & LAI & $\mathrm{m}^{2} \mathrm{~m}^{-2}$ & {$[0.00,7.99]$} \\
\hline
\end{tabular}

370 The Matlab ${ }^{\mathrm{TM}}$ Profiler (Matwoks Inc., Natick, MA, USA) was used to evaluate the computing time and 371 number of calls of the different functions of each model used during these simulations in each run. 372 These metrics, together with the total computation time and the number of unsuccessful runs -where the 373 energy balance does not succeed to converge to a solution-, were used to compare models' 374 performances.

\subsection{Comparison with SCOPE model. Forward simulation with observational datasets}

376 SCOPE and senSCOPE were also run forward using observational datasets from the study site of 377 Majadas de Tiétar, Cáceres, Spain (39 56' 24.68"N, $\left.5^{\circ} 45^{\prime} 50.27^{\prime \prime} \mathrm{W}\right)$. Observations -and when missing 378 estimates- of vegetation properties and forcing variables integrated at ecosystem scale were used to run 379 both models. Predicted fluxes and reflectance factors where compared with EC observations and 380 hyperspectral airborne imagery. 
3.2.1 Study site and datasets perpetuity. It is made available under aCC-BY 4.0 International license.

382 The study site is located in the experimental station of Majadas de Tiétar. It is a managed tree-grass

383 ecosystem combining sparse trees (Quercus ilex L. subsp. ballota [Desf.] Samp) and a highly diverse 384 herbaceous cover combining numerous species of three main functional plant forms: grasses, forbs and legumes. The climate is continental Mediterranean so that the grassland shows a strong seasonality initiated by greening phase around April, followed by a dry season that starts between May and June, a second re-greening driven by autumn rains, and a dormant phase during winter (El-Madany et al. 2018). The grassland phenology and functioning strongly responds to light and temperature in spring and to water availability in late spring-summer and in autumn (Luo et al. 2018). Several species grow and senesce at different times, usually, in early spring senescent material remnant from the winter is already present, then new material is also generated during spring, where $f_{\text {green }}$ can already be already as low as 0.7 (Melendo-Vega et al. 2018).

In this site, three EC towers monitor three areas of the same ecosystem, one of them fertilized with nitrogen $(\mathrm{N})$ and another one with $\mathrm{N}$ plus phosphorous $(\mathrm{P})$, and the control one with no fertilization. These towers include also eddy covariance systems around $15 \mathrm{~m}$ above the ground, providing ecosystem-level measurements of carbon and water fluxes. Three sub-canopy towers monitor grassland fluxes $~ 1.6 \mathrm{~m}$ aboveground. Details of the instrumentation and the manipulation can be found in ElMadany et al, (2018) and Perez-Priego et al, (2017). Also, a series of airborne campaigns with the Compact Airborne Spectrographic Imager CASI-1500i (Itres Research Ltd., Calgary, AB, Canada), operated by the Instituto Nacional de Técnica Aeroespacial (INTA) were conducted between 2012 and 2017. From a total of 17 images, a $R$ of the footprint of each EC tower and campaign was extracted. Details of methods and data processing can be found in Pacheco-Labrador et al., (2017). Additionally, 403 in each of the airborne campaigns, destructive sampling of vegetation provided estimates of ecosystem $404 L A I, f_{\text {green }}, C_{\mathrm{dm}}, C_{\mathrm{w}}$, Nitrogen concentration $\left(N_{\text {mass }}\right)$ and/or $C_{\mathrm{ab}}$ and $C_{\mathrm{ca}}$. Further information on protocols 405 and methods can be found in Melendo-Vega et al., (2018), Gonzalez-Cascon et al., (2017) and 406 (Gonzalez-Cascon and Martin 2018). 
bioRxiv preprint doi: https://doi.org/10.1101/2020.02.05.935064; this version posted February 6, 2020. The copyright holder for this preprint (which was not certified by peer review) is the author/funder, who has granted bioRxiv a license to display the preprint in perpetuity. It is made available under aCC-BY 4.0 International license.

\subsection{2 senSCOPE and SCOPE. Forward simulation and evaluation}

408 Observed/estimated forcing variables and vegetation properties were used to predict fluxes and 409 reflectance factors \pm 1 day around each flight campaign in each EC tower during daytime. Since no field 410 observations of all the vegetation parameters were available, some of them had to be estimated. When 411 missing, $C_{\mathrm{ab}}$ and $C_{\mathrm{ca}}$ were estimated from their relationship with $N_{\text {mass }}$ observed in the site. Also $V_{\text {cmax }}$ 412 was estimated as a function of $N_{\text {mass }}$ in the green leaves $\left(N_{\text {mass,green }}\right)$ following the relationship in Feng 413 and Dietze (2013), and assumed $45 \mu \mathrm{mol} \mathrm{m}^{-2} \mathrm{~s}^{-1}$ for tree leaves. A constant $m$ parameter of 10 was 414 assumed, $N$ and $L A D$ were assumed 1.5 and spherical, respectively. $C_{\mathrm{s}}$ was estimated from the 415 remaining leaf parameters inverting the statistical model described section 3.3.2 and in Appendix A. 416 Soil reflectance was determined by $S M_{\mathrm{p}}$ and the parameters estimated by inversion of the BSM model 417 (Verhoef et al. 2018) in Pacheco-Labrador et al (2019). Also, $r_{\mathrm{sS}}$ was estimated as function of $S M_{\mathrm{p}}$ 418 using the model in Pacheco-Labrador et al (2019).

419 Then, we evaluated the capability of both models to predict $G P P, \lambda E, R_{\mathrm{n}}, G$, and $H$ comparing SCOPE 420 and senSCOPE predictions with EC fluxes in the site. We also evaluated model performance and 421 structure using predicted fluxes and computing quantities that describe energy partitioning, the 422 evaporative fraction (Eq. 20)

$423 E F=\frac{\lambda E}{\lambda E+H}$,

424 where $\lambda E$ and $H$ are the total latent heat sensible heat fluxes, respectively.

425 Emitted irradiance in the TIR $\left(E_{\mathrm{t}}\right)$ was compared with net radiometer measurements in the EC towers 426 (CNR4, Kipp and Zonen, Delft, Netherlands); also $R$ were compared with those of the imagery at the 427 time of the overpass.

\section{8}

\subsection{Comparison with SCOPE model. Inversion on observational datasets}

429 In order to assess the impact of accounting for senescence material during the estimation of key 430 biophysical (e.g., $L A I, C_{\mathrm{ab}}$ ) and functional (e.g., $V_{\mathrm{cmax}}, m$ ) vegetation parameters, we compared the 431 parameter estimates and posterior predictions resulting from the inversion of both models against real 

perpetuity. It is made available under aCC-BY 4.0 International license.

432 observations in a Mediterranean grassland in the context of a nutrient manipulation experiment with $\mathrm{N}$

433 and $\mathrm{P}$, featuring $f_{\text {green }}$ between $0.05-1$. In this work, we inverted SCOPE and senSCOPE using the

434 inversion method and approaches proposed in Pacheco-Labrador et al. (2019).

\section{5}

436

\subsubsection{Study site and datasets}

The inversion the models is tested using field observations from the understory grass layer of the site of Majadas de Tiétar, Cáceres, Spain, acquired in the context of the Small-scale MANIpulation Experiment (SMANIE) (Perez-Priego et al. 2015). This manipulation nutrient experiment was performed in an open area to minimize the effect of trees. The experimental design consisted of 4 blocks (4 replicates each) with N, P, both (NP) additions, and the control treatment (C, not fertilized). As a result of the fertilization, N, NP and P treatments induced changes in plant community, plant structure and function (Martini et al. 2019; Migliavacca et al. 2017; Perez-Priego et al. 2015). 9 field campaigns took place between 2014-2016 covering spring and early summer. In each block, midday measurements were carried out in two different collars with a dual spectroradiometric system providing hyperspectral $R$ and SIF estimates in the $\mathrm{O}_{2}-\mathrm{A}\left(F_{760}\right)$ and the $\mathrm{O}_{2}-\mathrm{B}\left(F_{687}\right.$, not in all the campaigns). Diurnal time course of TIR up-welling radiance $\left(L_{\mathrm{t}}\right)$ and GPP was determined using gas exchange chambers from sunrise to sunset. Fluxes were collected quasi-simultaneously in the same collars of the radiometric measurements at midday. The mismatch between the radiometric and chamber measurements was minimum. Moreover, destructive sampling near by the collars provided estimates of plant traits ( $f_{\text {green }}, L A I$, and nitrogen concentration $\left.N_{\text {mass }}\right)$. Additional information about instrumentation, sampling methods and data processing can be found elsewhere (Martini et al. 2019; Migliavacca et al. 2017; Pacheco-Labrador et al. 2019; Perez-Priego et al. 2015).

\subsection{2 senSCOPE and SCOPE. Inversion and evaluation}

We inverted senSCOPE and SCOPE using the same datasets and methodology described for the inversion of SCOPE in Pacheco-Labrador et al. (2019). Observations of $R$ and $L_{\mathrm{t}}, F_{760}$ and/or GPP were used to estimate $L A I, C_{\mathrm{ab}}, V_{\mathrm{cmax}}, m$ and other biophysical parameters (Table 2) using an innovative methodology that combined biophysical and functional constraints in two different steps. Three 
bioRxiv preprint doi: https://doi.org/10.1101/2020.02.05.935064; this version posted February 6, 2020. The copyright holder for this preprint (which was not certified by peer review) is the author/funder, who has granted bioRxiv a license to display the preprint in perpetuity. It is made available under aCC-BY 4.0 International license.

458 different sets of constraints (inversion schemes) were tested, each combined in the first step of the

459 inversion (Step\#1), noon $R$ with noon $G P P\left(\mathrm{I}_{\mathrm{GPP}}\right)$, noon $G P P$ and $F_{760}\left(\mathrm{I}_{\mathrm{GPP}-\mathrm{SIF}}\right)$, or nothing else $\left(\mathrm{I}_{\mathrm{R}}\right)$.

460 Table 2. Parameters estimated inverting senSCOPE model

\begin{tabular}{|l|l|l|l|l|}
\hline Parameter & Symbol & Units & Step & Inversion bounds \\
\hline Leaf chlorophyll content & $C_{\mathrm{ab}}$ & $\mu \mathrm{g} \mathrm{cm}^{-2}$ & $\# 1$ & {$[0,100]$} \\
\hline Leaf carotenoids content & $C_{\mathrm{ca}}$ & $\mathrm{Mg} \mathrm{cm}^{-2}$ & $\# 1$ & {$[0,40]$} \\
\hline Senescent material & $C_{\mathrm{s}}$ & - & $\# 1$ & {$[0,7.5]$} \\
\hline Leaf water content & $C_{\mathrm{w}}$, & $\mathrm{g} \mathrm{cm}^{-2}$ & $\# 1$ & {$\left[6.3 \cdot 10^{-5}, 0.06\right]$} \\
\hline Leaf dry matter content & $C_{\mathrm{dm}}$ & $\mathrm{g} \mathrm{cm}^{-2}$ & $\# 1$ & {$[0.0019,0.03]$} \\
\hline Leaf structural parameter & $\mathrm{N}$ & $\mathrm{Layers}$ & $\# 1$ & {$[1,3.6]$} \\
\hline Leaf area index & $\mathrm{LAI}$ & $\mathrm{m}^{2} \mathrm{~m}^{-2}$ & $\# 1$ & {$[0,8]$} \\
\hline Leaf inclination distribution function & $\mathrm{LIDF}$ & - & $\# 1$ & {$[-1,1] ; \mid L I D F_{\mathrm{a}}$} \\
\hline Bimodality of the leaf inclination & $\mathrm{LIDF}$ & - & $\# 1$ & $\begin{array}{l}\text { LIDF } \\
\mathrm{b} \mid \leq 1\end{array}$ \\
\hline Maximum carboxylation capacity & $V_{\mathrm{cmax}}$ & $\mu \mathrm{mol} \mathrm{m}^{-2} \mathrm{~s}^{-1}$ & $\# 1 \& \# 2$ & {$[0,200]$} \\
\hline Ball-Berry sensitivity parameter & $\mathrm{m}$ & - & $\# 2$ & {$[0,50]$} \\
\hline Fluorescence quantum efficiency & $f_{\mathrm{qe}}$ & - & $\# 1 \& \# 2$ & {$[0,1]$} \\
\hline
\end{tabular}

462 In Step\#1 biophysical parameters of the SCOPE model and a first guess of $V_{\text {cmax }}$ were estimated. 463 Uncertainties were estimated using a Bayesian approach (Omlin and Reichert 1999). Then, in a second 464 step (Step\#2) the guess of $V_{\text {cmax }}$ was used as a prior and diel cycles of $L_{\mathrm{t}}$ combined with diel GPP (I $\left.\mathrm{I}_{\mathrm{GPP}}\right)$, 465 diel GPP and noon $F_{760}\left(\mathrm{I}_{\mathrm{GPP}-\mathrm{SIF}}\right)$, or only diel $L_{\mathrm{t}}\left(\mathrm{I}_{\mathrm{R}}\right)$ were used to estimate the functional parameters $466 V_{\mathrm{cmax}}$ and $m$. $f_{\mathrm{qe}}$ was estimated in both steps in the schemes $\mathrm{I}_{\mathrm{SIF}}$ and $\mathrm{I}_{\mathrm{GPP}-\mathrm{SIF}}$. Also, pattern-oriented model 467 evaluation was used to assess the results of the different schemes. Unlike the previous work, this time 20 

perpetuity. It is made available under aCC-BY 4.0 International license.

468 we increased the inversion bounds (Table 2) for $C_{\mathrm{dm}}$ and $C_{\mathrm{w}}$ according to observed distributions in the

469 site (Martín et al. 2019; Melendo-Vega et al. 2018). Also, since previous works found problems to

470 cover the range of $R$ in the near infrared, $C_{\mathrm{s}}$ upper bound was raised up to 7.5 a.u.; a value that allowed covering the low $R$ values found in dry periods in the ecosystem (Martín et al. 2019). The multiple constraint inversion approach proposed in Pacheco-Labrador et al. (2019) provided coherent parameter estimates when GPP constrained the inversion ( $\mathrm{I}_{\mathrm{GPP}}$ and $\mathrm{I}_{\mathrm{GPP}-\mathrm{SIF}}$ ) using SCOPE; however, uncertainties in part related to the presence of senescent materials biased the estimation some of the parameters, notably $C_{\mathrm{ab}}$ during the dry season. In all the cases senescent material also was suspected to induce underestimation of $L A I$.

We used the same methodology to invert senSCOPE on the same datasets in order to compare the results provided by both models and to understand the suitability of using senSCOPE in environments featuring large fractions of senescent leaves. However, in the case of senSCOPE, 6 leaf parameters of two different leaf types must be estimated (Table 2). In order limit the number of free parameters in the inversion, we applied the following constraints: We assumed that green leaves presented no senescent pigments $\left(C_{\mathrm{s}}=0\right)$ whereas senescent leaves only presented senescent pigments $\left(C_{\mathrm{ab}}=C_{\mathrm{ca}}=0\right)$. We also assumed that the mesophyll parameter $(N)$ and dry matter content $\left(C_{\mathrm{dm}}\right)$, were the same for both types of leaves, whereas that water content $\left(C_{\mathrm{w}}\right)$ of green leaves was four times higher than senescent $C_{\mathrm{w}}$ (Kidnie et al. 2015). This allowed us reducing the degrees of freedom by 6. We assumed that average leaf parameters $(X)$ could be computed as a linear combination of the parameters of each leaf type $\left(X_{\text {green }}\right.$ and $\left.X_{\text {senes }}\right)$ as in Eq. 21:

489 Given the constrains imposed on leaf parameters, we could directly optimize the leaf averaged 490 parameters in the inversion, similarly as parameters are retrieved in the inversion of SCOPE (Pacheco491 Labrador et al. 2019). To do so, $X_{\text {green }}$ or $X_{\text {senes }}$ are internally calculated solving them from Eq. 21; which 492 is possible in all the cases since at least the value one of them together with $f_{\text {green }}$ are known: Either they 493 are equal, 0 , or their ratio has been prescribed. senSCOPE includes the additional parameter $f_{\text {green}}$; in 494 order to reduce equifinality and as well as the number of parameters to estimate we prescribed $f_{\text {green }}$ by 21 

perpetuity. It is made available under aCC-BY 4.0 International license.

495 modelling it as a function of the averaged leaf parameters $X$ using a Neural Network (NN). The NN was

496 trained from a look up table of individual $X_{\text {green }}$ and $X_{\text {senes }}$ parameters averaged as a function of $f_{\text {green}}$; no

497 assumptions on $N, C_{\mathrm{w}}$ and $C_{\mathrm{dm}}$ were made (Appendix A). As a result, the same parameters were

498 estimated in the inversion of SCOPE and senSCOPE.

499 As in Pacheco-Labrador et al. (2019), we used pattern-oriented model evaluation approach to assess the 500 retrieval of functional parameters, which cannot be determined from individual leaf measurements in 501 the highly biodiverse grassland under study. To do so, we assessed the relationship of $V_{\mathrm{cmax}}$ and $C_{\mathrm{ab}}$ 502 against $N_{\text {mass }}$ in the green fraction of the canopy ( $N_{\text {mass,green }}$ ), and in the case of $V_{\text {cmax }}$ it was compared 503 with the relationship published by Feng and Dietze (2013) for grasslands. We also evaluated model 504 performance and structure using not directly predicted fluxes, but variables derived from them such as 505 EF, which describes energy partitioning (Eq. 19). In addition, a more traditional evaluation was also 506 done assessing the goodness of the fit or prediction of model constraints $\left(R, L_{t}, F_{760}\right.$, and/or $\left.G P P\right)$ and 507 observed parameters (LAI, $\left.f_{\text {green }}\right)$.

\section{Results}

\subsection{Comparison of results and performance with SCOPE model: Sensitivity analysis.}

510 For the $\mathrm{F}_{\text {meteo }}$ runs, green and senescent leaf properties were kept constant for the different combinations

511 of $f_{\text {green. }}$ Fig. 3a,b show the leaf optical properties simulated with senSCOPE and SCOPE, respectively.

512 Accordingly Fig. 3c,d shows the TOC Hemispherical-Directional Reflectance Factors (HDRF)

513 simulated with each model at midday of DoY 139, the timestamp used for $\mathrm{F}_{\mathrm{veg}}$ runs. As can be seen,

514 senSCOPE predicts spectroradiometric variables that vary more proportionally to $f_{\text {green }}$, whereas SCOPE 515 simulates stronger absorptions, especially in the visible region. This results from allocating all the 516 absorptive substances to a single leaf type. The largest differences between models are found in the red 517 and blue regions, where senescent leaves in senSCOPE increase scattering. We also verified that when $518 f_{\text {green }}$ equals 1 or 0 , the output of both models is the same. 
bioRxiv preprint doi: https://doi.org/10.1101/2020.02.05.935064; this version posted February 6, 2020. The copyright holder for this preprint (which was not certified by peer review) is the author/funder, who has granted bioRxiv a license to display the preprint in perpetuity. It is made available under aCC-BY 4.0 International license.

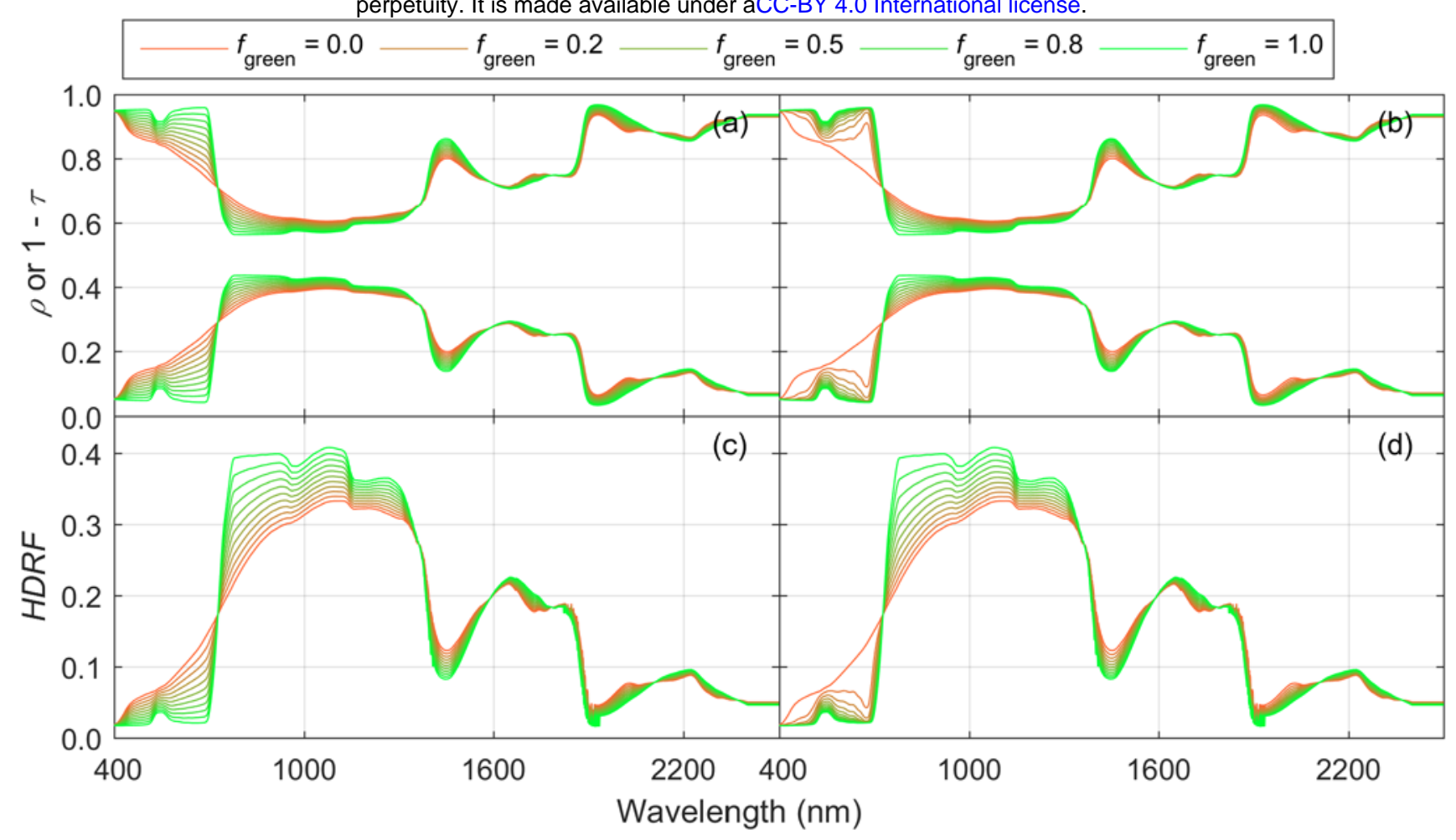

520 Figure 3. Leaf reflectance and transmittance factors predicted by senSCOPE (a) and SCOPE (b); and top 521 of the canopy Hemispherical Directional Reflectance Factors predicted by senSCOPE (c) and SCOPE (d) 522 for different fractions of green and senescent leaves.

523 Fig. 4 compares some of the spectoradiometric variables and fluxes predicted by senSCOPE (left semi524 columns) and SCOPE (right semi-columns) during DoY 139 in the $\mathrm{F}_{\text {meteo }}$ runs. As can be seen, those 525 variables that are strongly controlled by radiative transfer in the optical domain ( $A P A R_{\mathrm{Chl}}$ (Fig. 4c,d), 526 the Photochemical Reflectance Index (PRI, Gamon et al, (1992)), sensitive to activation of the 527 xanthophyll cycle (Fig. 4q,r) and $F_{760}$ (Fig. 4s,t)) present a stronger and more linear sensitivity to $f_{\text {green }}$. 528 The same is observed for the water and energy fluxes ( $\lambda E$ (Fig. 4e,f) and $H$ (Fig. 4g,h)). Differences for 529 variables related with the radiative transfer of thermal radiance seem to be lower $\left(R_{\mathrm{n}}(\mathrm{Fig} .4 \mathrm{i}, \mathrm{j})\right.$ and $T_{\mathrm{c}}$ 530 (Fig. 4k,l)). senSCOPE leaves feature a higher absorption of $P A R$ per unit green leaf area, which 531 produces a stronger NPQ activation $\left(K_{\mathrm{n}}(\right.$ Fig. $4 \mathrm{~m}, \mathrm{n})$ ), and a depletion of photosynthetic efficiency 532 around midday $\left(\Phi_{f}{ }_{f}\right.$ (Fig. 4o,p)) for low $f_{\text {green }}$ (unlike the other parameters, these are only representative 533 of green leaves). Notice that the example shown is only representative of the meteorological and 
bioRxiv preprint doi: https://doi.org/10.1101/2020.02.05.935064; this version posted February 6, 2020. The copyright holder for this preprint (which was not certified by peer review) is the author/funder, who has granted bioRxiv a license to display the preprint in perpetuity. It is made available under aCC-BY 4.0 International license.

534 vegetation properties represented during DoY 139, and the differences shown should not be taken

535 generally.

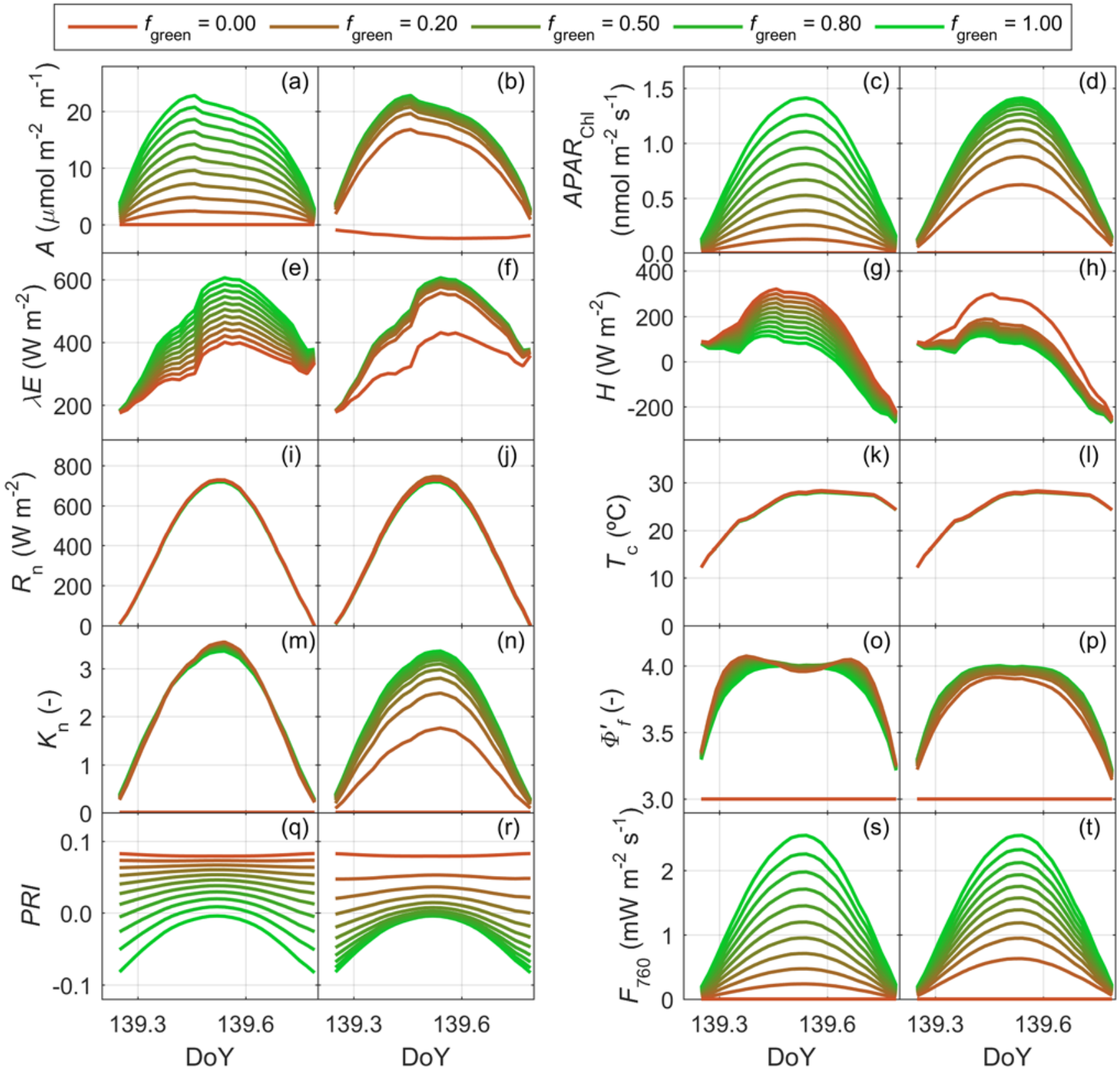

537 Figure 4. Diel cycles of senSCOPE (left semi-column) and SCOPE (right semi-column) predicted variables 538 on DoY 136: Assimilation (a,b), photosynthetically active radiation absorbed by chlorophylls (c,d), latent 539 (d,e) and sensible heat fluxes (g,h), net radiation (i,j), canopy temperature (k,l), rate coefficient for non- 
bioRxiv preprint doi: https://doi.org/10.1101/2020.02.05.935064; this version posted February 6, 2020. The copyright holder for this preprint (which was not certified by peer review) is the author/funder, who has granted bioRxiv a license to display the preprint in perpetuity. It is made available under aCC-BY 4.0 International license.

540 photochemical quenching $(\mathbf{m}, \mathbf{n})$, fluorescence efficiency $(\mathbf{0 , p})$, photochemical reflectance index (q,r) and 541 TOC fluorescence radiance at $760 \mathrm{~nm}(\mathrm{~s}, \mathrm{t})$.

542 Fig. 5 shows the distributions of the difference between fluxes predicted by SCOPE and (minus) 543 senSCOPE for each $f_{\text {green }}$ level. Results of the $\mathrm{F}_{\text {meteo }}$ and the $\mathrm{F}_{\mathrm{veg}}$ simulations are shown in the left and 544 the right columns, respectively. As can be seen, both under varying meteorological conditions and 545 varying plant properties, the two models predict the same fluxes when $f_{\text {green }}=1$, but not always when $546 f_{\text {green }}=0$. For $f_{\text {green }}<1$ SCOPE predicts higher assimilation (A, Fig. 5a,b); but in the case of $f_{\text {green }}=0$, 547 where SCOPE predicts negative $A$ due to photorespiration, and senSCOPE represents no photosynthetic 548 leaf area. SCOPE also predicts in most of the cases higher $R_{\mathrm{n}}$ (Fig. 5c,d) and $\lambda E$ (Fig. 5e,f), and lower $H$ 549 (Fig. 5g,h) and G (Fig. 5i,j). 
bioRxiv preprint doi: https://doi.org/10.1101/2020.02.05.935064; this version posted February 6, 2020. The copyright holder for this preprint (which was not certified by peer review) is the author/funder, who has granted bioRxiv a license to display the preprint in perpetuity. It is made available under aCC-BY 4.0 International license.
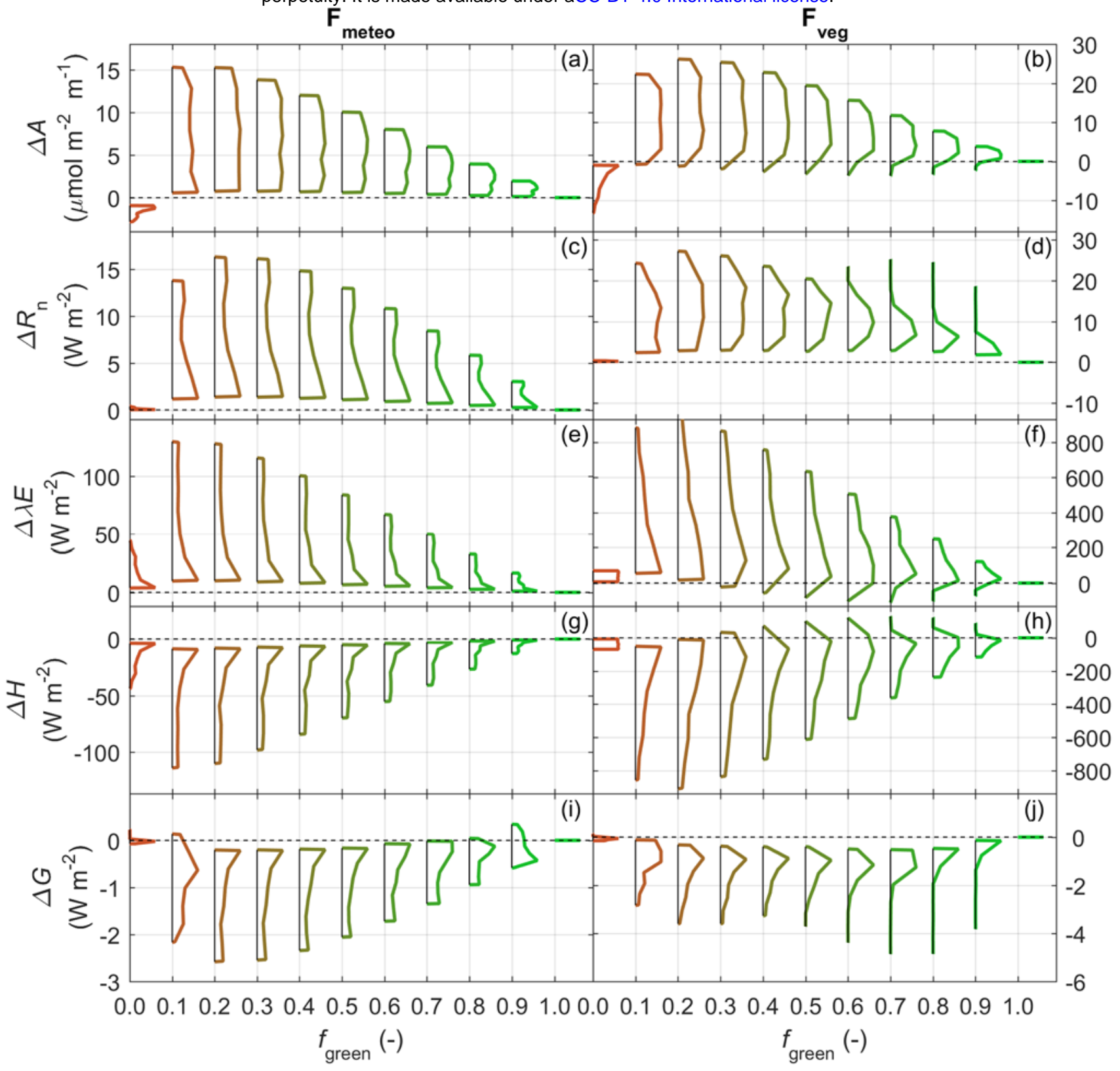

551 Figure 5. Distributions of the difference between the fluxes simulated with SCOPE and (minus) senSCOPE 552 in the $\mathbf{F}_{\text {meteo }}$ run (left column) and the $\mathbf{F}_{\text {veg }}$ run (right column) for different fractions of green leaf area: 553 assimilation (a,b), net radiation (c,d), latent heat flux (e,f), sensible heat flux (g,h) and soil heat flux (i,j). 
bioRxiv preprint doi: https://doi.org/10.1101/2020.02.05.935064; this version posted February 6, 2020. The copyright holder for this preprint (which was not certified by peer review) is the author/funder, who has granted bioRxiv a license to display the preprint in perpetuity. It is made available under aCC-BY 4.0 International license.

556 Differences between predicted fluxes usually maximize when $C_{\mathrm{ab}}$ and $L A I$ increase (Fig. S1a-e and S2

557 a-e, respectively). $G$ (and $R_{\mathrm{n}}$ ) also present large differences for low values of these parameters and mid

$558 f_{\text {green }}$. In the analysis of the forward runs, the differences observed from $\mathrm{F}_{\mathrm{veg}}$ simulations are often larger

559 than those $\mathrm{F}_{\text {meteo }}$ simulations since the variability in the meteorological variables is -in relative terms-

560 lower than the variability simulated for the vegetation properties.

561 For each $f_{\text {green }}$ level, Fig. 6 presents the distribution of the difference between variables related to leaf 562 function, as predicted by SCOPE and (minus) senSCOPE. Results of $F_{\text {meteo }}$ and $F_{\text {veg }}$ are shown on the

563 left and the right columns, respectively. Similar to the fluxes, these variables are integrated according to $564 L A I$ and the probability of each sunlit and shaded leaf angle. $A P A R_{\mathrm{Chl}}$ (Fig. 6a,b) is equal for both 565 models when the canopy is totally green or senescent. For the rest of the cases SCOPE predicts higher $566 A P A R_{\mathrm{Chl}}$, except some cases when $C_{\mathrm{ab}}<10 \mu \mathrm{g} \mathrm{cm}^{-2}$ (not shown). senSCOPE predicts higher canopy 567 temperature $\left(T_{\mathrm{c}}\right.$, Fig. 6c,d) than SCOPE; the largest differences are found when $C_{\mathrm{ab}}$ is high (Fig. S1g), 568 or when $L A I$ is low (Fig. S2g). Simlarly, $u W U E$ (Fig. 6e,f) is higher for senSCOPE, but unlike $T_{\mathrm{C}}$ and 569 most of the variables compared, differences in $u W U E$ are more strongly controlled by meteorological 570 conditions than by vegetation parameters. The largest differences in $u W U E$ are found under cold 571 conditions with $V P D<5$ hPa (not shown). senSCOPE presents also higher $K_{\mathrm{n}}$ (Fig. 6g,h). Differences 572 between models predictions increase with $L A I$ (Fig. S2i), and decrease with $C_{\mathrm{ab}}$ (Fig. S1i). $\Phi_{f}{ }_{f}($ Fig. 5i,j) 573 is most often higher for senSCOPE than for SCOPE, especially if $L A I$ is high and $C_{\mathrm{ab}}$ is low (not 574 shown). On the other hand, SCOPE predicts higher $\Phi_{f}{ }_{f}$ when $L A I$ is low (Fig. S2j) or when $C_{a b}$ is low 575 and $L A I$ is moderate (Fig. S1j). As expected, both models predict the same values for these variables 576 when $f_{\text {green }}=1$. 
bioRxiv preprint doi: https://doi.org/10.1101/2020.02.05.935064; this version posted February 6, 2020. The copyright holder for this preprint (which was not certified by peer review) is the author/funder, who has granted bioRxiv a license to display the preprint in perpetuity. It is made available under aCC-BY 4.0 International license.

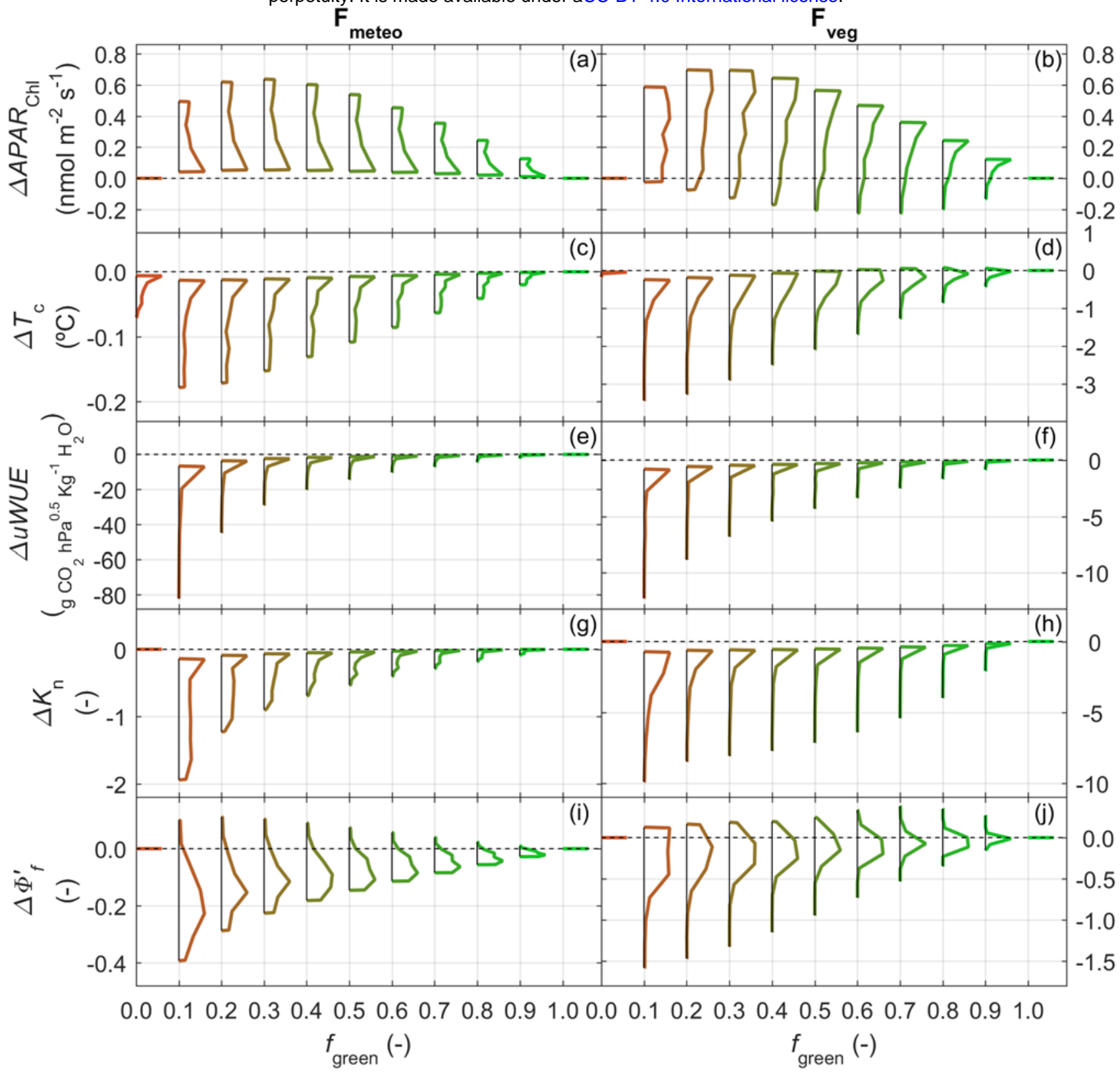

Figure 6. Distributions of the difference between variables indicative of plant physiology simulated with SCOPE and (minus) senSCOPE in the $F_{\text {meteo }}$ run (left column) and the $F_{\text {veg }}$ run (right column) for different fractions of green leaf area: photosynthetically active radiation absorbed by chlorophylls (a,b), canopy temperature (c,d), underlying water use efficiency (e,f), rate coefficient for non-photochemical quenching (g,h) and fluorescence efficiency $(i, j)$. 
bioRxiv preprint doi: https://doi.org/10.1101/2020.02.05.935064; this version posted February 6, 2020. The copyright holder for this preprint (which was not certified by peer review) is the author/funder, who has granted bioRxiv a license to display the preprint in perpetuity. It is made available under aCC-BY 4.0 International license.

584 Fig. 7 shows the distribution of some TOC spectroradiometric variables predicted by SCOPE and

585 (minus) senSCOPE for each $f_{\text {green }}$ level. Results of the $\mathrm{F}_{\text {meteo }}$ and the $\mathrm{F}_{\text {veg }}$ simulations are presented in the

586 left and the right columns, respectively. $F_{687}$ (Fig. 7a,b) and $F_{760}$ (Fig. 7c,d) are larger for SCOPE in

587 most of the cases the cases; the largest differences are found for low $f_{\text {green }}$ and large $C_{\mathrm{ab}}$ (Fig. S1k,l) and

588 LAI (Fig. S2k,l). Differences in PRI are negative for Fmeteo, but of both signs for Fveg (Fig. 7e,f). In

589 this case, the influence of vegetation parameters is more complex and less linear than in other variables;

590 since it depends on the combination of $C_{\mathrm{ab}}$ and $C_{\mathrm{ca}}$, their ratio and $L A I$ (not shown). A similar analysis

591 carried out on the PRI computed from reflectance factors where the effect of the xanthophyll cycle is

592 not simulated reveals that differences between models rather respond to biophysical properties than to

593 differences in function (not shown). Two more spectral indices responsive to pigments content and

594 canopy structure are also analysed. Fig. 7g,h presents the differences for the Normalized Difference

595 Vegetation Index (NDVI, Rouse et al, (1974)); Fig. 7i,j present differences for the MERIS Terrestrial

596 Chlorophyll Index (MTCI, Dash and Curran (2007)); senSCOPE predicts lower and higher values,

597 respectively. For these indices, the absolute difference between models increase as $f_{\text {green }}$ decreases, and

598 as $C_{\mathrm{ab}}$ and $L A I$ increase (Fig. S1n,o and S2n,o, respectively). 
bioRxiv preprint doi: https://doi.org/10.1101/2020.02.05.935064; this version posted February 6, 2020. The copyright holder for this preprint (which was not certified by peer review) is the author/funder, who has granted bioRxiv a license to display the preprint in perpetuity. It is made available under aCC-BY 4.0 International license.
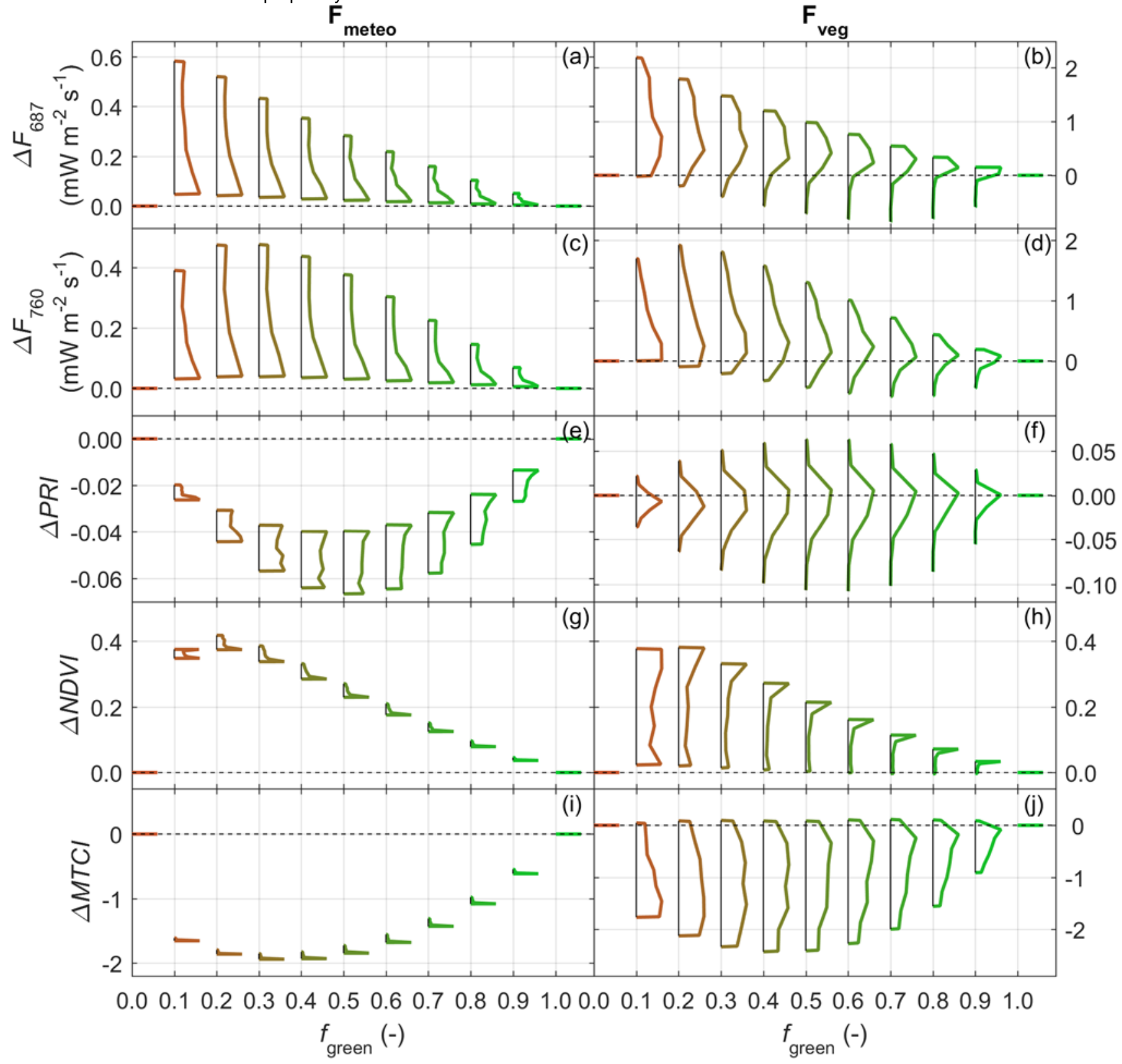

601 Figure 7. Distributions of the difference between spectral variables indicative of plant physiology, 602 structure and biochemical composition simulated with SCOPE and senSCOPE in the $F_{\text {meteo }}$ run (left column) and the $F_{\text {veg }}$ run (right column) for different fractions of green leaf area: TOC fluorescence radiance at $687 \mathrm{~nm}(\mathrm{a}, \mathrm{b})$, TOC fluorescence radiance at $760 \mathrm{~nm}(\mathrm{c}, \mathrm{d})$, photochemical reflectance index 606 including effects of xanthophyll cycle (e,f), normalized difference vegetation index (g,h) MERIS terrestrial chlorophyll index (i,j). 
bioRxiv preprint doi: https://doi.org/10.1101/2020.02.05.935064; this version posted February 6, 2020. The copyright holder for this preprint (which was not certified by peer review) is the author/funder, who has granted bioRxiv a license to display the preprint in perpetuity. It is made available under aCC-BY 4.0 International license.

\section{7}

608

609

610

611

612

613

614

615

616

617

618

619

620

\subsection{Comparison with SCOPE model. Forward simulation with observational datasets}

Fig. 8 compares the different variables predicted by SCOPE and senSCOPE vs. the fluxes measured by

the EC towers and $R$ acquired by the airborne hyperspectral imager in the site of Majadas de Tiétar. The comparison is done using Total Least Squares (Golub and Loan 1980). In general, senSCOPE achieves higher coefficients of determination $\left(R^{2}\right) \mathrm{n}$ lower relative root mean squared errors (RRMSE). Both models overestimate high $R$ (Fig. 8a), and GPP (Fig. 8b); but senSCOPE is less deviated. SCOPE overestimates $\lambda E$ and $E F$, and underestimates $H$ more than senSCOPE. Both models predict $R_{\mathrm{n}}$ quite accurately and precisely; but senSCOPE predicts $R_{\mathrm{n}}, E_{\mathrm{t}}$ and $G$ with slightly larger errors and in some cases lower $R^{2}$ than SCOPE.

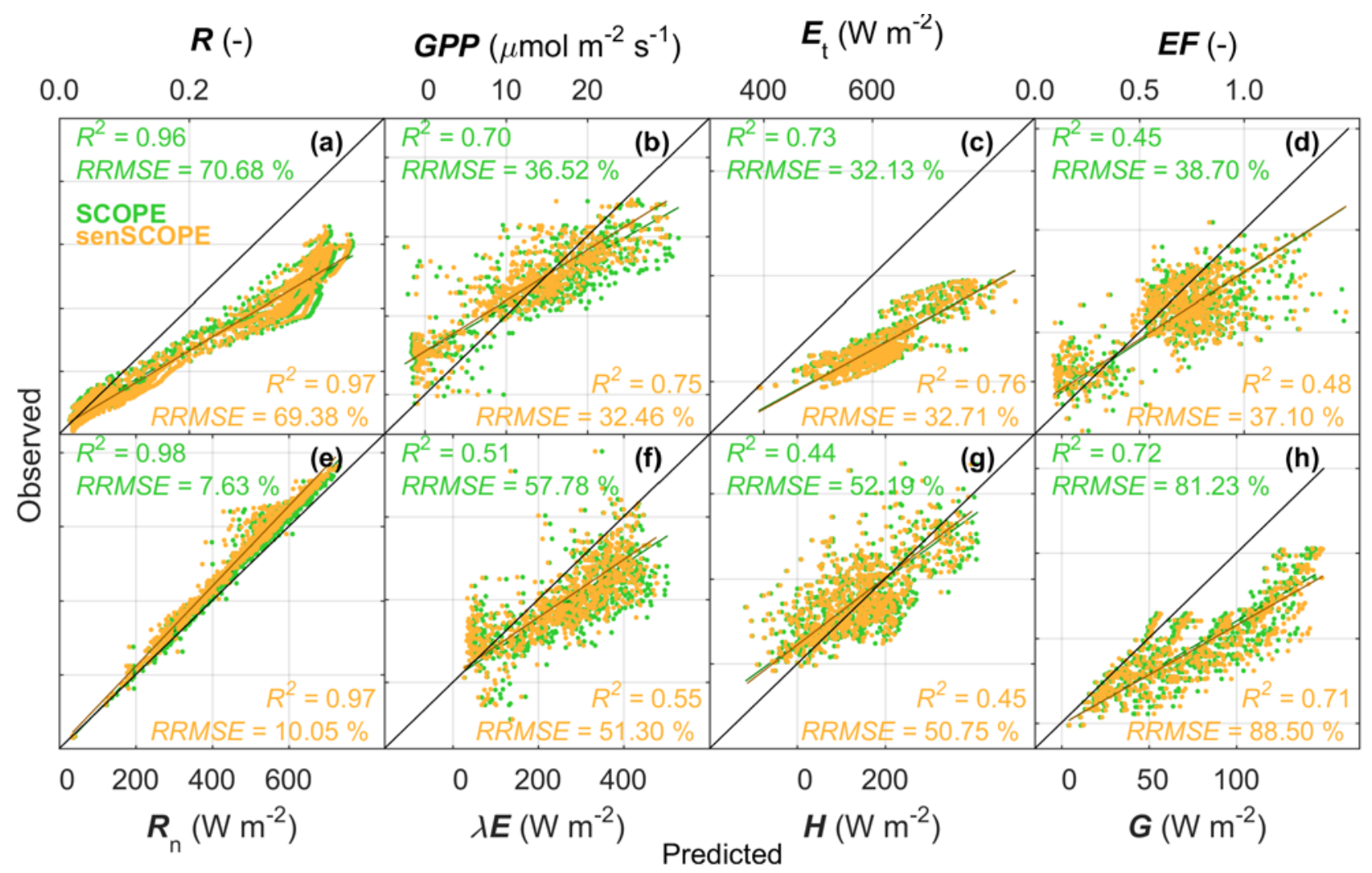

Figure 8. Comparison of observed and predicted fluxes and reflectance factors at ecosystem scale. Predictions are done by SCOPE (green) and senSCOPE (orange) using field observations or estimates of vegetation properties, as well as forcing variables measured at the research station of Majadas de Tiétar \pm 1 day around different airborne campaigns. 
bioRxiv preprint doi: https://doi.org/10.1101/2020.02.05.935064; this version posted February 6, 2020. The copyright holder for this preprint (which was not certified by peer review) is the author/funder, who has granted bioRxiv a license to display the preprint in perpetuity. It is made available under aCC-BY 4.0 International license.

\subsection{Comparison with SCOPE model. Inversion on observational datasets}

622 Fig. 9 summarizes the capability of SCOPE and senSCOPE to fit/predict the variables used as inversion

623 constraints in the different schemes tested; notice that not all the constraints are used to optimize 624 parameters in all the schemes. The relative differences between the statistics of the fit are calculated as $625\left(100 \cdot\left(x_{\text {SenSCOPE }}-x_{\mathrm{SCOPE}}\right) / x_{\mathrm{SCOPE}}\right)$; where $x$ is the statistic and the respective model is presented in the 626 subscript. $R^{2}$ is estimated using Total Least Squares (Golub and Loan 1980), and the relative root mean 627 squared error (RRMSE) and mean average error (MAE) result of the comparison of the 628 observed/predicted values. Posterior uncertainty $\left(\sigma_{\text {post }}\right)$ is estimated according to Omlin and Reichter 629 (1999). The relative differences of $R$ in the visible spectral region $\left(R_{\mathrm{Vis}}\right.$, Fig. 9a-d) and the near infrared 630 ( $R_{\mathrm{NIR}}$, Fig. 9e-h), GPP (Fig. 9i-l), $F_{760}$ (Fig. 9m-p) and $L_{\mathrm{t}}($ Fig. 9q-t) are presented for the three different 631 inversion schemes tested. $R$ is used in all the inversion schemes. senSCOPE fits $R_{\mathrm{Vis}}$ and $R_{\mathrm{NIR}}$ more 632 poorly than SCOPE in the schemes $\mathrm{I}_{\mathrm{GPP}}$ and $\mathrm{I}_{\mathrm{GPP}-\mathrm{SIF}}$; whereas in the case of $\mathrm{I}_{\mathrm{R}}$ senSCOPE these are 633 better fit and posterior uncertainties are lower than for SCOPE. senSCOPE slightly improves the fit of $634 G P P$ when this is a constraint of the inversion; however, $\sigma_{\text {post }}$ almost duplicate (values $\sim 80 \%$, out of the 635 plot scale). As in Pacheco-Labrador et al., (2019) $\mathrm{I}_{\mathrm{R}}$ fails to accurately fit GPP, but $\sigma_{\text {post }}$ is lower for 636 senSCOPE. senSCOPE fit of $F_{760}$ improves respect to SCOPE when this is a constraint of the inversion 637 ( $\left.\mathrm{I}_{\mathrm{GPP}-\mathrm{SIF}}\right)$, but $\sigma_{\mathrm{post}}$ increase in all the cases. senSCOPE fits $L_{\mathrm{t}}$ more poorly than SCOPE, but $\sigma_{\text {post }}$ 638 decrease in all the cases. 
bioRxiv preprint doi: https://doi.org/10.1101/2020.02.05.935064; this version posted February 6, 2020. The copyright holder for this preprint (which was not certified by peer review) is the author/funder, who has granted bioRxiv a license to display the preprint in perpetuity. It is made available under aCC-BY 4.0 International license.

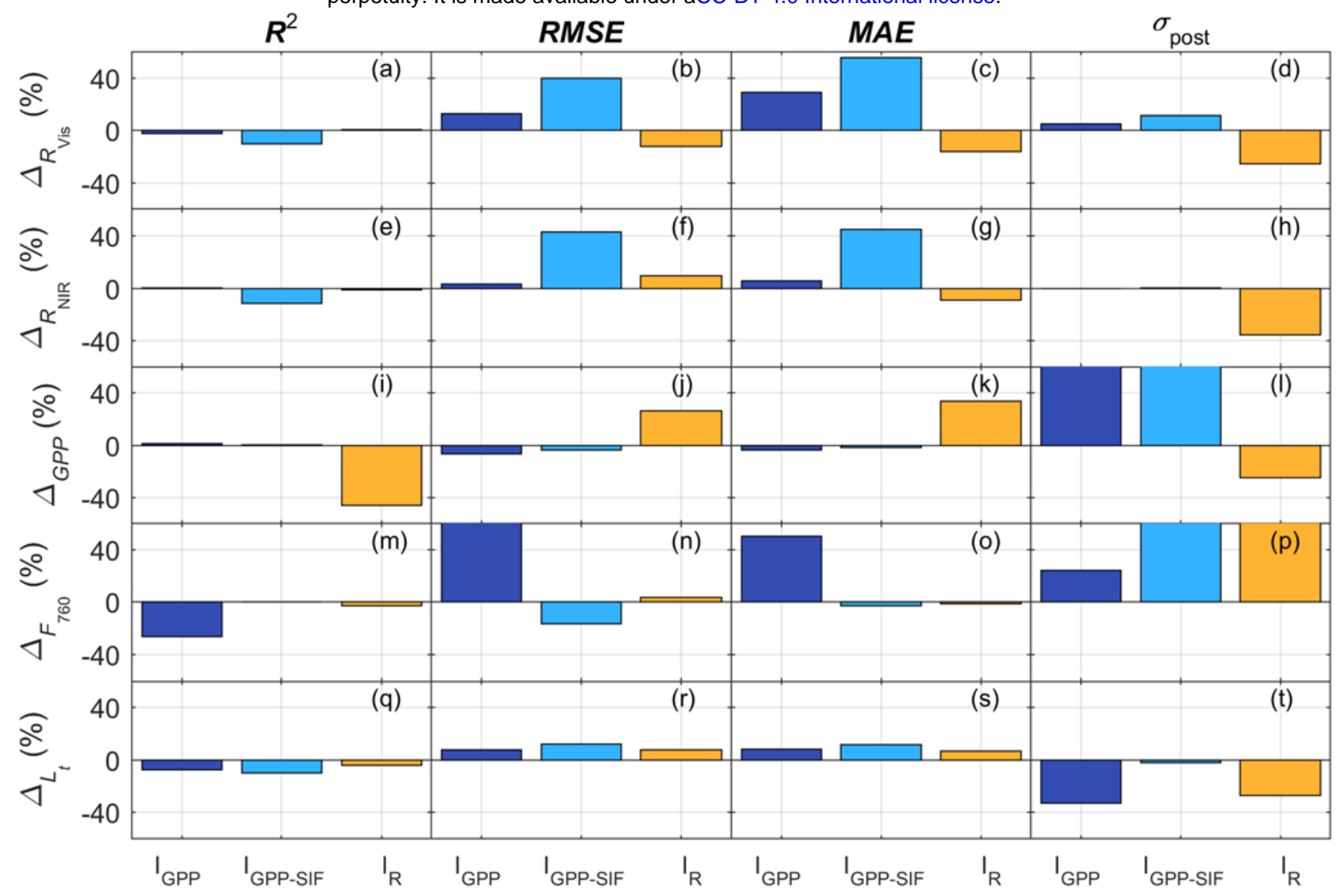

640 Figure 9. Relative difference between the fit/prediction statistics of the inversion constraints obtained by 641 senSCOPE and SCOPE for the different inversion schemes.

642 Fig. 10 compares the most relevant model parameters estimated by SCOPE and senSCOPE for the 643 different inversion schemes tested (presented by columns, from left to right: $\mathrm{I}_{\mathrm{GPP}}, \mathrm{I}_{\mathrm{GPP}-\mathrm{SIF}}, \mathrm{I}_{\mathrm{R}}$ ).

644 Parameters are evaluated both using field observations and pattern-oriented model evaluation approach.

645 LAI (Fig. 10a-c) and $f_{\text {green }}$ (Fig. 10d-f) are compared against observations using Total Least Squares 646 (Golub and Loan 1980). As can be seen, senSCOPE predicts similar LAI values but show higher $R^{2}$ and 647 significance. senSCOPE is also capable of providing reasonable estimates of $f_{\text {green }}$, these are often 648 overestimated but still within the bounds of the relationship $C_{\mathrm{ab}}-f_{\text {green }}$ observed in the site (Fig. S3). $649 N_{\text {mass,green }}$ is used to evaluate $V_{\text {cmax }}$ (Fig. 10g-i) and to compare the relationship between both variables 650 with the one reported in the literature for grasslands (Feng and Dietze 2013). Notice that senSCOPE 
bioRxiv preprint doi: https://doi.org/10.1101/2020.02.05.935064; this version posted February 6, 2020. The copyright holder for this preprint (which was not certified by peer review) is the author/funder, who has granted bioRxiv a license to display the preprint in perpetuity. It is made available under aCC-BY 4.0 International license.

$651 V_{\text {cmax }}$ is provided per unit green leaf area and is thus comparable with SCOPE estimates and the

652 literature data. Results are coherent with those presented in Pacheco-Labrador et al., (2019), $I_{R}$ fails to

653 constrain $V_{\text {cmax }}$, whereas the schemes using GPP provide relationships with $N_{\text {mass,green }}$ which are closer 654 to those in the literature. $V_{\mathrm{cmax}}$ estimates are very similar for both models in $\mathrm{I}_{\mathrm{GPP}}$; however, the use of $655 F_{760}$ in $\mathrm{I}_{\mathrm{GPP}-\mathrm{SIF}}$ seems to slightly deviate the adjusted logarithmic model from the one fit to the data in 656 Feng and Dietze (2013). Similarly, $C_{\mathrm{ab}}$ (per total leaf area) is evaluated against $N_{\text {mass }}$ of the whole 657 canopy (Fig. 10j-l), and their relationship is compared with field observations of both variables in the 658 site of Majadas de Tiétar. When GPP constrains the inversion senSCOPE and SCOPE estimates are 659 similar and follow the relationship observed in the field. However, as in Pacheco-Labrador et al., 660 (2019), SCOPE $\mathrm{I}_{\mathrm{GPP}}$ and $\mathrm{I}_{\mathrm{GPP}-\mathrm{SIF}}$ estimates present high values during the dry period, which stand out of 661 the relationship with $N_{\text {mass }}$ between 0.5-1.3\%. senSCOPE corrects most of these values, especially in 662 the scheme $\mathrm{I}_{\mathrm{GPP}}$; while the scheme $\mathrm{I}_{\mathrm{GPP}-\mathrm{SIF}}$ still preserves some of these high values. Fig. 10m-o 663 compares predicted and observed EF using Total Least Squares (Golub and Loan 1980). In general, 664 both models achieve similar results when GPP constrains the inversion; however, senSCOPE $R^{2}$ are 665 lower than in SCOPE. As in Pacheco-Labrador et al., (2019), $\mathrm{I}_{\mathrm{R}}$ fails to constrain functional parameters. 
bioRxiv preprint doi: https://doi.org/10.1101/2020.02.05.935064; this version posted February 6, 2020. The copyright holder for this preprint (which was not certified by peer review) is the author/funder, who has granted bioRxiv a license to display the preprint in perpetuity. It is made available under aCC-BY 4.0 International license.

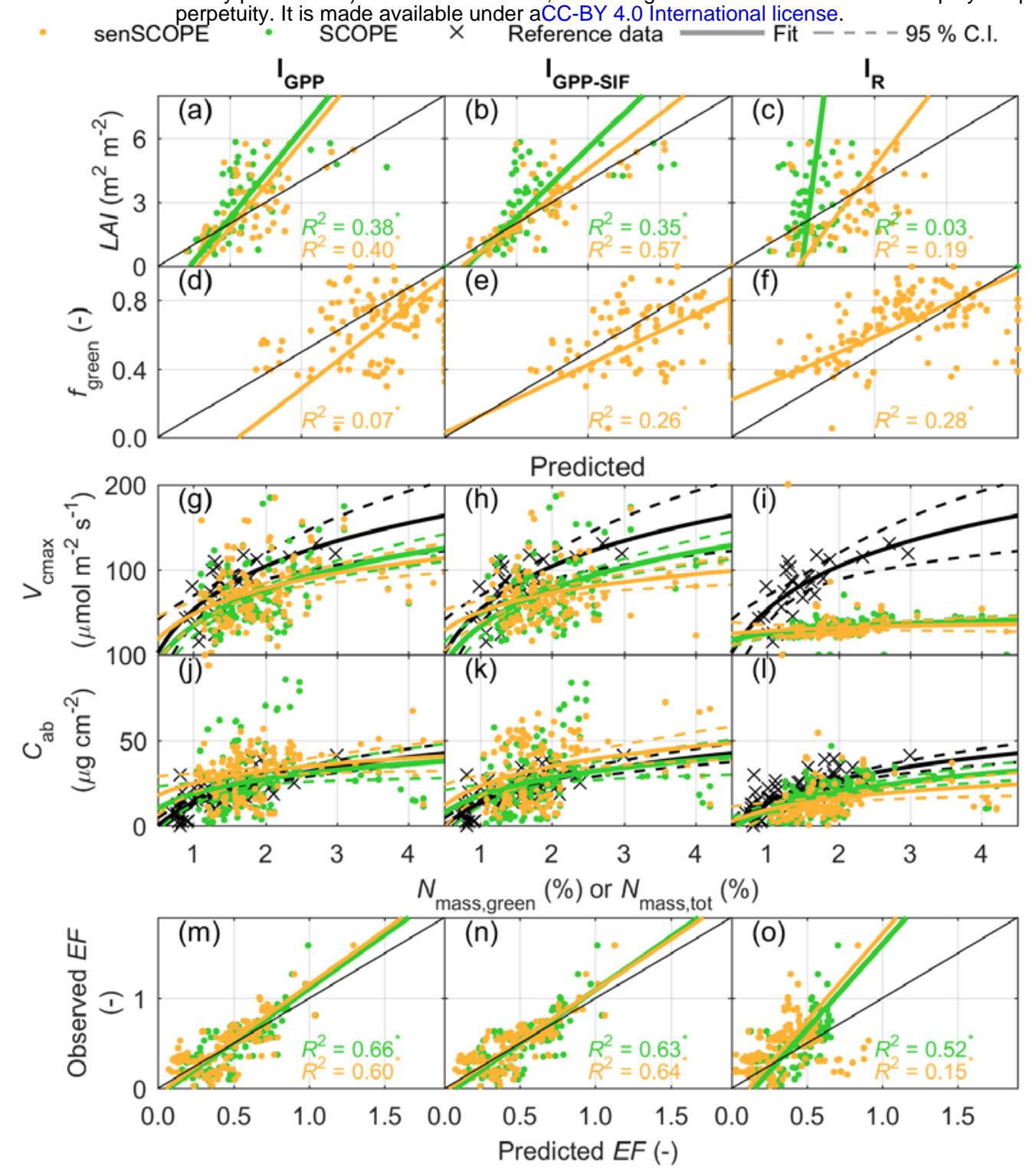

667 Figure 10. Summary of the parameters' evaluation using observations and pattern-oriented model 668 evaluation for the four inversion schemes tested. Leaf area index, (a-c) and green fraction of leaf surface 669 (d-f), and evaporative fraction (q-t) are compared with field observation using Total Least Squares (Golub and Loan 1980). Significance is described with the symbols ${ }^{\circ}$ for $p$-values $0.05 \leq p<0.10$; and ${ }^{*}$ for $p<0.05$. The 1:1 line is shown in black. Maximum carboxylation rate (g-i) and chlorophyll concentration (j-p) are evaluated against nitrogen content in green leaves and total nitrogen content, respectively and compared with data from the literature (Feng and Dietze 2013) the first, and relationships observed in the field, the second A logarithmic relationship is fit in both cases, the $95 \%$ confidence interval is show with dashed

675 lines. 
677 This manuscript describes and evaluates senSCOPE, a version of the model SCOPE representing

678 separately radiative transfer and physiological processes of green and senescent leaves; which is

679 relevant in canopies featuring important senescent leaf area fractions. senSCOPE is evaluated against

680 SCOPE 1) by direct comparison of forward synthetic simulations, 2) by comparison of simulated and

681 observed ecosystem-scale fluxes and reflectance factors, and 3) by evaluation of parameter estimates

682 and predicted variables via inversion of the models against a comprehensive dataset including

683 hyperspectral optical $R$, as well as GPP, SIF and TIR radiance. These data were collected in a

684 fertilization experiment with varying nitrogen and phosphorous additions and degrees of water stress.

685 Results show that in senescent canopies senSCOPE improves the forward modelling of radiative 686 transfer, photosynthesis and fluxes; and that in inversion -if suitably constrained-, it improves the 687 estimation of $C_{\mathrm{ab}}$. At the same time, the performance of both models is comparable when green leaves 688 dominate.

689 senSCOPE distributes senescent and remaining pigments in two conceptual leaves (green and 690 senescent) and predicts separately their respective optical properties, which are later combined. This 691 approach was already proposed by Bach et al., (2001) and used in later works (Bach and Verhoef 2003; 692 Houborg et al. 2009; Houborg et al. 2015; Houborg and McCabe 2016; Verhoef and Bach 2003). This 693 dual-leaf approach generates averaged "brighter” leaves since not all the absorbent species are located 694 in the same leaf (Fig. 3). This has relevant consequences for the canopy-RTM, especially in those 695 spectral regions where senescent and the rest of the pigments overlap, and therefore for $A P A R_{\mathrm{Chl}}$. 696 senSCOPE produces reflectance factors and $A P A R_{\mathrm{Chl}}$ that close-to-linearly vary with $f_{\text {green}}$; whereas in 697 the case of SCOPE, these variables vary logarithmically with $f_{\text {green }}$ since leaves absorptivity saturate due 698 to the large presence of pigments. This saturation, combined with the fact that $R_{\mathrm{NIR}}$ was overestimated 699 during senescence, led to unrealistically high $C_{a b}$ estimates during the dry period when a strong 700 functional constraint -GPP- was used (Pacheco-Labrador et al. 2019). Notice that only the constraint 701 GPP provided robust estimates of functional parameters. In the present work, we repeated the inversion 702 of SCOPE allowing higher $C_{\mathrm{s}}$ than in Pacheco-Labrador (2019) since this allowed predicting low $R_{\mathrm{NIR}}$ 

perpetuity. It is made available under aCC-BY 4.0 International license.

703 values observed in the site (Martín et al. 2019). This approach improved the fit of $R_{\mathrm{NIR}}$ for all inversion

704 schemes during SCOPE inversion (not shown), but did not solve the overestimation of $C_{\mathrm{ab}}$ in the most

705 strongly constrained schemes ( $\mathrm{I}_{\mathrm{GPP}}$ and $\mathrm{I}_{\mathrm{GPP}-\mathrm{SIF}}$, Fig. 10a,b). senSCOPE fitted less precisely the

706 inversion constraints, and in some cases posterior uncertainties increased due to the strong control that

$707 f_{\text {green }}$ has on most of the model outputs (Fig. 9). For $\mathrm{I}_{\mathrm{R}}$ senSCOPE improved the fit of $R$, but the opposite

708 occurred when $a P A R$ was constrained by GPP, suggesting that the model might not still represent

709 accurately the observed grassland However, senSCOPE led to $C_{\mathrm{ab}}$ values more soundly related with

$710 N_{\text {mass }}$ than SCOPE during the dry season (schemes $\mathrm{I}_{\mathrm{GPP}}$ and $\mathrm{I}_{\mathrm{GPP}-S I F}$, Fig. 10j,k).

711 The fact that senSCOPE limits photosynthesis and transpiration to the green fraction results in a close-

712 to-linear relation between $f_{\text {green }}$ on the one hand, and $A$ and $\lambda E$ on the other hand (Fig. 4 and 5). SCOPE 713 predicts higher assimilation and transpiration unless $f_{\text {green }}$ is very low $(\sim 0)$; in that case $A$ is negative

714 while $\lambda E$ is still high. Contrarily, $R_{\mathrm{n}}$ and $G$ predictions are similar for both models; also, differences in $H$

715 are lower than for $\lambda E$, but still in senSCOPE $H$ varies more linearly with $f_{\text {green }}$ than in SCOPE (notice

716 that $f_{\text {green }}$ is not a SCOPE parameter, but is used to average leaf parameters). In the forward simulation at

717 ecosystem scale senSCOPE predicted most of the ecosystem fluxes better than SCOPE (Fig. 8). In this

718 case we assumed a fixed value for $m$, which might be not completely realistic; however additional

719 works at ecosystem scale have shown that senSCOPE can more robustly represent water use efficiency

720 than SCOPE (not shown). In the inversion at plot level, senSCOPE predicted GPP better than SCOPE

721 when used as constraint (Fig. 9k-0). In contrast, EF was predicted more poorly in all the schemes.

722 senSCOPE assumes no transpiration from senescent leaves; however evaporation from their surface 723 might be relevant when these are moisturized by dew or rainfall. Neither SCOPE nor senSCOPE 724 represent that process and their use after such situations might result uncertain.

725 In inversion, both SCOPE and senSCOPE underestimated LAI, while senSCOPE overestimated $f_{\text {green }}$ 726 (Fig. 10a-h). As discussed in Pacheco-Labrador et al, (2019) and Melendo-Vega (2018), the optical 727 properties of dry standing material might not be accurately described by RTM, leading to an 728 overestimation of $R_{\mathrm{NIR}}$, which seems to be counter-weighted in inversion by reducing LAI. In fact, 729 inversion schemes using GPP ( $\mathrm{I}_{\mathrm{GGP}}$ and $\mathrm{I}_{\mathrm{GPP}-\mathrm{SIF}}$ ) improved the estimation of LAI since GPP demands 

perpetuity. It is made available under aCC-BY 4.0 International license.

730 higher $A P A R_{\mathrm{Chl}}$ in exchange for increasing the fitting error of $R_{\mathrm{NIR}}$ (Pacheco-Labrador et al., (2019), this

731 work). In senSCOPE, underestimation of $L A I$ was also compensated also by overestimating $f_{\text {green. }}$ These

732 facts suggest that the optical properties of the senescent material and/or the death standing material of

733 this grassland (and likely other ecosystems) are not accurately represented, leading to biased estimates

734 of some of the parameters. In fact, it was necessary increasing the upper bound of $C_{\mathrm{s}}$ to be able to 735 predict low $R_{\mathrm{NIR}}$ in the dry season. We allowed $C_{\mathrm{s}}$ up to 7.5; whereas values up to 5.0 are reported in 736 literature (Houborg and Anderson 2009). Too high $C_{\mathrm{s}}$ might have led to unrealistic representation of $\rho$ 737 and $\tau$ of senescent leaves, very dark in the visible region but also with low $R_{\mathrm{NIR}}$. In some cases SCOPE 738 estimated $C_{\mathrm{s}}=7.5$, whereas senSCOPE predicted $C_{\mathrm{s}}<5$ in most of the cases (Fig. S4c). Apart from $739 L A I, C_{\mathrm{dm}}$ and $C_{\mathrm{w}}$, -which are weakly constrained because the spectroradiometric measurements did not 740 include the short wave infrared range (SWIR)-, might have been affected by this problem. SCOPE and 741 senSCOPE estimates of $C_{\mathrm{dm}}$ often hit the upper bound stablished from observations in the field. High $742 C_{\mathrm{dm}}$ also serves to reduce $R_{\mathrm{NIR}}$. In contrast, senSCOPE $C_{\mathrm{w}}$ estimates are less often saturated; $C_{\mathrm{w}}$ has 743 little effect below $970 \mathrm{~nm}$, but influences leaf optical properties in the SWIR. The relationship between $744 N, C_{\mathrm{dm}}$ and $C_{\mathrm{w}}$ of green and senescent leaves assumed during inversion might have contributed to 745 increase the uncertainty of the parameter estimates; for example, it has been observed that leaf thickness 746 decreases during senescence (Castro and Sanchez-Azofeifa 2008); whereas other works assign high N 747 values to senescent leaves (Houborg et al. 2009). However, a balance between model error and 748 equifinality must be also observed. Site-specific relationships between the parameters of each leaf type or relationships found in global databases could be used in the future to improve the representation of semi-arid canopies. senSCOPE does not include improved calibrated absorption coefficients or refractive indices to more realistically represent senescent leaves and death standing material, but it offers a formally more correct representation of mixed canopies. The model improves the representation 753 of these canopies, which could be used in the future to calibrate or validate specific absorption spectra 754 of senescent material. senSCOPE can also be applied to other canopies, such as crops and forests, which 755 are characterized a senescent stage. Moreover, the approach adopted in senSCOPE could be similarly 756 used to represent other mixed canopies combining plants with different biophysical properties and 757 function, such as C3 and C4 species. An additional problem for the representation of mixed canopies 38 
would be the vertical distribution of the senescent material. The impact on the observed $R$ and fluxes is unclear, and further research is needed in this direction. In such studies, senSCOPE could also be extended to other versions of SCOPE, such as mSCOPE (Yang et al. 2017) to describe the vertical distribution of senescent matter.

$f_{\text {green }}$ is a critical parameter in senSCOPE, it strongly controls RTM and fluxes and increases equifinality of the inverse problem. Thus, the use of prior information about is this variable is strongly recommended during inversion. For this reason, in this work $f_{\text {green }}$ was indirectly predicted from leaf parameter estimates using a NN while the model was inverted. The design of this model was critical to achieve acceptable results, and during training $C_{\mathrm{ab}}$ (and $C_{\mathrm{ca}}$ ) had to be limited to the ranges observed in the study site (up to $\sim 40 \mu \mathrm{g} \mathrm{cm}^{-2}$ ). During inversion higher $C_{\mathrm{ab}}$ values were allowed, but still, $C_{\mathrm{ab}}-f_{\text {green }}$ estimates stood within or very close to the bounds observed and used to train the NN (Fig. S3)

As a result of the combination of changes in RTM and photosynthesis, not only carbon and water fluxes, but also photosynthetic efficiency and downregulation resulted modified (Fig. 6). On one side, senSCOPE tends to predict higher canopy temperatures than SCOPE, especially when $f_{\text {green }}$ decreases. Senescent leaves are warmer than green leaves, but senSCOPE green leaves are not necessarily cooler than SCOPE leaves (not shown). Leaf temperature strongly influences photosynthetic efficiency and together with $A P A R_{\mathrm{Chl}}$ on photosynthesis down-regulation. Fig. 4m, h show how senSCOPE diel cycles of $K_{\mathrm{n}}$ reach higher midday values than SCOPE. SCOPE predicts larger variability of $K_{\mathrm{n}}$ as a function of $f_{\text {green }}$ under conditions of low illumination, whereas senSCOPE $K_{\mathrm{n}}$ varies more strongly with $f_{\text {green }}$ under high temperature and irradiance conditions (not shown). Non-photochemical quenching has also different effects on the predicted $\Phi^{\prime}{ }_{f}$. For example, Fig. 4o,p show how senSCOPE predicts a decrease of this efficiency at midday whereas this is hardly noticeable for SCOPE. $K_{\mathrm{n}}$ and $\Phi_{f}$, are fundamental variables to mechanistically interpret SIF signals to determine functional status of vegetation and stress (Frankenberg and Berry 2018; Porcar-Castell et al. 2014). Thus considering the differences shown, both models can lead to very different interpretations. Adequate representation of physiological processes and their drivers is fundamental to mechanistically interpret these signals; but also the representation of the spectral variables used to obtain information about these processes, such as fluorescence radiance or 
$P R I$. Similarly as $R$, spectral indices vary more linearly with $f_{\text {green }}$ in senSCOPE than in SCOPE (e.g.,

Fig. 4q,r). Unlike other spectroradiometric variables, PRI show no clear differences between models

(e.g. distributions of the difference centre around 0). PRI is known to result sensitive to pigments pool, ratio and to LAI (Gamon and Berry 2012; Garbulsky et al. 2011); results of this work also show that this index is also strongly sensitive to the presence of senescent material. The magnitude of SIF emissions is also modified by senSCOPE, which tends to predict less SIF when $f_{\text {green }}$ decreases, (Fig. 7a-d).

In this study we compare the inversion of SCOPE and senSCOPE using the data and approaches of in Pacheco-Labrador et al, (2019), but allowing for higher values for $C_{\mathrm{s}}$ (as well as $C_{\mathrm{dm}}$ and $C_{\mathrm{w}}$ ). The wider parameter bounds did not change significantly the results obtained with SCOPE, and differences were mainly related to the use of senSCOPE; which improved the estimation of $C_{\mathrm{ab}}$ in the dry season. As with SCOPE, SIF (not shown) and $R$ failed to constrain functional parameters (e.g., $V_{\text {cmax }}$ ) and LAI; and only inversion schemes relying on GPP provided robust estimates. However with senSCOPE, the schemes relying on SIF reduced their performance respect to SCOPE. $\mathrm{I}_{\mathrm{GPP}-\mathrm{SIF}}$ fitted the inversion constraints more poorly, and could not correct high $C_{\mathrm{ab}}$ estimates during senescence as much as $\mathrm{I}_{\mathrm{GPP}}$. This might be result from the use of large $C_{\mathrm{s}}$, which suggests further work is needed to more accurately 801 functional parameters resulted insensitive to $I_{R}$ constraints (partly due to inversion method, see 802 Pacheco-Labrador et al, (2019)). Bayat et al., (2018) inverted SCOPE using $R$ and found troubles to 803 predict low GPP and $\lambda \mathrm{E}$ in a grassland during senescence, which was corrected constraining the model 804 with $R$ and TIR radiance to reduce $V_{\text {cmax }}$ during this period. Fig. 10i-l compares $V_{\text {cmax }}$ estimates of both 805 models; for senSCOPE $V_{\text {cmax }}$ is presented respect to green leaf area, whereas in SCOPE, it is presented 806 respect to total leaf area (all considered "green"). As can be seen, when adequately constrained 807 estimates of both models are comparable. In senSCOPE GPP scales with $f_{\text {green }}$, and $V_{\text {cmax }}$ (in the green 808 leaves) does not need to decrease to predict low assimilation.

809 senSCOPE is computationally more demanding (around 10\% slower) than SCOPE since more 810 processes and calculations are needed, and more iterations are required to close the energy balance 811 (Table S5). However, senSCOPE seems more robust and provides lower energy balance closure error. 
bioRxiv preprint doi: https://doi.org/10.1101/2020.02.05.935064; this version posted February 6, 2020. The copyright holder for this preprint (which was not certified by peer review) is the author/funder, who has granted bioRxiv a license to display the preprint in perpetuity. It is made available under aCC-BY 4.0 International license.

812 Since performance of both models is similar for large $f_{\text {green }}$, both models can be alternately used through

813 the season according the presence of senescent material.

\section{6. Conclusions}

815 The combination of advanced radiative transfer models with models representing exchanges of matter 816 and energy between vegetation, soil and atmosphere is bringing new opportunities to improve our 817 understanding of ecosystem function from remote observations. For example, the model SCOPE is

818 being used in the last years with this purpose. However, the accuracy with which these models represent 819 reality limits their application; and ecosystem-specific features can bias results and their interpretation. 820 In this context, we present the model senSCOPE; which adapts SCOPE radiative transfer, energy 821 balance, photosynthesis and transpiration in homogeneous canopies with mixed green and dry leaves.

822 The separated representation of green and senescent leaves significantly modifies the simulation of 823 fluxes and spectra signals respect to a model featuring a single leaf with “averaged” properties. 824 senSCOPE reflectance factors, carbon assimilation and water and energy fluxes linearly scale with $f_{\text {green}}$; 825 it also improves the prediction of these variables in forward simulations as well as the estimation of 826 vegetation parameters, notably $C_{\mathrm{ab}}$, during the dry season. This is significant for the remote sensing of 827 vegetation function of semi-arid ecosystems, and potentially for phenology monitoring. Despite the 828 improvements, results suggest that not only model structure needs to be corrected; a more accurate 829 characterization of the optical properties of senescent material in grasslands is still needed. The use of 830 SCOPE and derived models is growing in the remote sensing community; however, further assessment 831 of their performance to inform about plant function should be tested in different ecosystems. For 832 example, the role of vertical and horizontal heterogeneity is still unclear. Robust evaluation, e.g. 833 pattern-oriented model evaluation approach, would contribute to identify caveats and ecosystem834 specific features that prevent accurate monitoring of their function; and that therefore, should be also 835 represented. 

perpetuity. It is made available under aCC-BY 4.0 International license.

\section{Appendix A: Green fraction Neural Network predictor}

837 In senSCOPE inversion, the fraction of green leaf area in the canopy $\left(f_{\text {green }}\right)$ is estimated as a function of

838 the canopy averaged leaf RTM parameters using a NN model trained form simulated data. Latin

839 Hypercube Sampling was used to generate a look-up table (LUT) with 5000 samples of different leaf

840 constituents $\left(C_{\mathrm{ab}}, C_{\mathrm{ant}}, C_{\mathrm{dm}}, C_{\mathrm{w}}, C_{\mathrm{s}}\right), N$ and $f_{\mathrm{green}}$. $C_{\mathrm{ca}}$ was included in the LUT as a function of $C_{\mathrm{ab}}$

841 according to the relationship reported in Sims and Gamon (2002), and an uncertainty estimated in the

842 relationship of $\sim 4.5 \mu \mathrm{g} \mathrm{cm}^{-2}$ according to field measurements was used to add Gaussian noise. The same

843 bounds that were applied in inversion (Section 3.3.2) were used to design the LUTs; however $C_{\mathrm{ab}}$ and

$844 C_{\text {са }}$ of green leaves were limited to 40 and $10 \mu \mathrm{g} \mathrm{cm}^{-2}$, respectively; according to field observations.

845 LUT values were assumed to belong to pure green and senescent leaves, and averaged leaf parameters

846 were mixed according with Eq. 21, assuming that in green leaves $C_{\mathrm{s}}=0$, and that in senescent leaves

$847 C_{\mathrm{ab}}=0, C_{\mathrm{ca}}=0, C_{\mathrm{ant}}=0$. No additional assumptions about the values of the parameters of each leaf type

848 and therefore the $N, C_{\mathrm{dm}}, C_{\mathrm{w}}$ were taken directly from the LUT.

849 A NN was trained using SimpleR (Camps-Valls et al. 2012) to predict $f_{\text {green }}$ as function of the canopy 850 averaged leaf RTM parameters. During the training, $60 \%$ of the dataset was used for fitting and $40 \%$

851 for testing. Performance statistics are presented in Table A1.

852 Table A1. Statistics of the fraction green leaf area $\left(f_{\text {green }}\right)$ Neural Network $(\mathrm{NN})$ model.

\begin{tabular}{|l|l|l|l|l|}
\hline Dataset & $R^{2}$ & RMSE & ME & MAE \\
\hline Training & 0.818 & 0.123 & 0.005 & 0.093 \\
\hline Validation & 0.718 & 0.230 & 0.158 & 0.180 \\
\hline
\end{tabular}

\section{Code availability}

854 senSCOPE code and further developments, as well as the code for the multiple constraint inversion of

855 the model are publicly available at https://github.com/JavierPachecoLabrador/senSCOPE. 
bioRxiv preprint doi: https://doi.org/10.1101/2020.02.05.935064; this version posted February 6, 2020. The copyright holder for this preprint (which was not certified by peer review) is the author/funder, who has granted bioRxiv a license to display the preprint in perpetuity. It is made available under aCC-BY 4.0 International license.

\section{6}

857

858

859

\section{0}

861

862

863

864

865

866

867

868

869

870

871

872

873

\section{References}

875 Anderson, R.C. (2006). Evolution and origin of the Central Grassland of North America: climate, fire, 876 and mammalian grazers. The Journal of the Torrey Botanical Society, 133, 626-647, 622

877 Bach, H., Schneider, K., Verhoef, W., Stolz, R., Mauser, W., Van Leeuwen, H., Schouten, L., \& 878 Borgeaud, M. (2001). Retrieval of geo-and biophysical information from remote sensing through 879 advanced combination of a land surface process model with inversion techniques in the optical and 880 microwave spectral range. 
bioRxiv preprint doi: https://doi.org/10.1101/2020.02.05.935064; this version posted February 6, 2020. The copyright holder for this preprint (which was not certified by peer review) is the author/funder, who has granted bioRxiv a license to display the preprint in perpetuity. It is made available under aCC-BY 4.0 International license.

881 Bach, H., \& Verhoef, W. (2003). Sensitivity studies on the effect of surface soil moisture on canopy 882 reflectance using the radiative transfer model GeoSAIL. In, IGARSS 2003. 2003 IEEE International 883 Geoscience and Remote Sensing Symposium. Proceedings (IEEE Cat. No.03CH37477) (pp. 1679-1681)

884 Bacour, C., Jacquemoud, S., Leroy, M., Hautecœur, O., Weiss, M., Prévot, L., Bruguier, N., \& Chauki, 885 H. (2002). Reliability of the estimation of vegetation characteristics by inversion of three canopy reflectance models on airborne POLDER data. Agronomie, 22, 555-565

Bayat, B., van der Tol, C., \& Verhoef, W. (2018). Integrating satellite optical and thermal infrared observations for improving daily ecosystem functioning estimations during a drought episode. Remote Sensing of Environment, 209, 375-394

Braswell, B.H., Schimel, D.S., Privette, J.L., Moore Iii, B., Emery, W.J., Sulzman, E.W., \& Hudak,

A.T. (1996). Extracting ecological and biophysical information from AVHRR optical data: An integrated algorithm based on inverse modeling. Journal of Geophysical Research: Atmospheres, 101, 23335-23348

894

895

896

897

898

899

900

901

902

903

904

905

906

907

908

909

910

911

912

913

914

915

916

Camino, C., Gonzalez-Dugo, V., Hernandez, P., \& Zarco-Tejada, P.J. (2019). Radiative transfer Vcmax estimation from hyperspectral imagery and SIF retrievals to assess photosynthetic performance in rainfed and irrigated plant phenotyping trials. Remote Sensing of Environment, 111186

Camps-Valls, G., Munoz-Mari, J., Gomez-Chova, L., Guanter, L., \& Calbet, X. (2012). Nonlinear Statistical Retrieval of Atmospheric Profiles From MetOp-IASI and MTG-IRS Infrared Sounding Data. IEEE Transactions on Geoscience and Remote Sensing, 50, 1759-1769

Castro, K.L., \& Sanchez-Azofeifa, G.A. (2008). Changes in Spectral Properties, Chlorophyll Content and Internal Mesophyll Structure of Senescing Populus balsamifera and Populus tremuloides Leaves. Sensors (Basel, Switzerland), 8, 51-69

Cleland, E.E., Chiariello, N.R., Loarie, S.R., Mooney, H.A., \& Field, C.B. (2006). Diverse responses of phenology to global changes in a grassland ecosystem. Proceedings of the National Academy of Sciences, 103, 13740

Croft, H., Chen, J.M., Luo, X., Bartlett, P., Chen, B., \& Staebler, R.M. (2017). Leaf chlorophyll content as a proxy for leaf photosynthetic capacity. Global Change Biology, 23, 3513-3524

Dash, J., \& Curran, P.J. (2007). Evaluation of the MERIS terrestrial chlorophyll index (MTCI). Advances in Space Research, 39, 100-104

Dutta, D., Schimel, D.S., Sun, Y., van der Tol, C., \& Frankenberg, C. (2019). Optimal inverse estimation of ecosystem parameters from observations of carbon and energy fluxes. Biogeosciences, 16, 77-103

El-Madany, T.S., Reichstein, M., Perez-Priego, O., Carrara, A., Moreno, G., Pilar Martín, M., PachecoLabrador, J., Wohlfahrt, G., Nieto, H., Weber, U., Kolle, O., Luo, Y.-P., Carvalhais, N., \& Migliavacca, M. (2018). Drivers of spatio-temporal variability of carbon dioxide and energy fluxes in a Mediterranean savanna ecosystem. Agricultural and Forest Meteorology, 262, 258-278 
bioRxiv preprint doi: https://doi.org/10.1101/2020.02.05.935064; this version posted February 6, 2020. The copyright holder for this preprint (which was not certified by peer review) is the author/funder, who has granted bioRxiv a license to display the preprint in perpetuity. It is made available under aCC-BY 4.0 International license.

917 Feng, X., \& Dietze, M. (2013). Scale dependence in the effects of leaf ecophysiological traits on

918 photosynthesis: Bayesian parameterization of photosynthesis models. New Phytologist, 200, 1132-1144

919 Feret, J.-B., François, C., Asner, G.P., Gitelson, A.A., Martin, R.E., Bidel, L.P.R., Ustin, S.L., le Maire,

920 G., \& Jacquemoud, S. (2008). PROSPECT-4 and 5: Advances in the leaf optical properties model

921 separating photosynthetic pigments. Remote Sensing of Environment, 112, 3030-3043

922

923

924

925

926

927

928

929

930

931

932

933

934

935

936

937

938

939

940

941

942

943

944

945

946

947

948

949

950

Féret, J.B. (2009). Apport de la modélisation pour l'estimation de la teneur en pigments foliaires par télédétection. In (p. 214): Université Pierre et Marie Curie

Féret, J.B., Gitelson, A.A., Noble, S.D., \& Jacquemoud, S. (2017). PROSPECT-D: Towards modeling leaf optical properties through a complete lifecycle. Remote Sensing of Environment, 193, 204-215

Figueroa, M.E., \& Davy, A.J. (1991). Response of Mediterranean Grassland Species to Changing Rainfall. Journal of Ecology, 79, 925-941

Frankenberg, C., \& Berry, J. (2018). 3.10 - Solar Induced Chlorophyll Fluorescence: Origins, Relation to Photosynthesis and Retrieval A2 - Liang, Shunlin. Comprehensive Remote Sensing (pp. 143-162). Oxford: Elsevier

Friedlingstein, P., Meinshausen, M., Arora, V.K., Jones, C.D., Anav, A., Liddicoat, S.K., \& Knutti, R. (2014). Uncertainties in CMIP5 Climate Projections due to Carbon Cycle Feedbacks. Journal of Climate, 27, 511-526

Gamon, J.A., \& Berry, J.A. (2012). Facultative and constitutive pigment effects on the Photochemical Reflectance Index (PRI) in sun and shade conifer needles. Israel Journal of Plant Sciences, 60, 85-95

Gamon, J.A., Peñuelas, J., \& Field, C.B. (1992). A narrow-waveband spectral index that tracks diurnal changes in photosynthetic efficiency. Remote Sensing of Environment, 41, 35-44

Garbulsky, M.F., Peñuelas, J., Gamon, J., Inoue, Y., \& Filella, I. (2011). The photochemical reflectance index (PRI) and the remote sensing of leaf, canopy and ecosystem radiation use efficiencies: A review and meta-analysis. Remote Sensing of Environment, 115, 281-297

Golub, G.H., \& Loan, C.F.v. (1980). An Analysis of the Total Least Squares Problem. SIAM Journal on Numerical Analysis, 17, 883-893

Gonzalez-Cascon, R., Jiménez-Fenoy, L., Verdú-Fillola, I., \& Martín, M.P. (2017). Short communication: Aqueous-acetone extraction improves the drawbacks of using dimethylsulfoxide as solvent for photometric pigment quantification in Quercus ilex leaves. 2017, 26

Gonzalez-Cascon, R., \& Martin, M.P. (2018). Protocol for pigment content quantification in herbaceous covers: sampling and analysis, October 2019

Guyot, S., Vercauteren, J., \& Cheynier, V. (1996). Structural determination of colourless and yellow dimers resulting from $(+)$-catechin coupling catalysed by grape polyphenoloxidase. Phytochemistry, 42, $1279-1288$ 
bioRxiv preprint doi: https://doi.org/10.1101/2020.02.05.935064; this version posted February 6, 2020. The copyright holder for this preprint (which was not certified by peer review) is the author/funder, who has granted bioRxiv a license to display the preprint in perpetuity. It is made available under aCC-BY 4.0 International license.

951 He, Y., \& Mui, A. (2010). Scaling up Semi-Arid Grassland Biochemical Content from the Leaf to the

952 Canopy Level: Challenges and Opportunities. Sensors, 10, 11072-11087

953 Henry, H.A.L., Brizgys, K., \& Field, C.B. (2008). Litter Decomposition in a California Annual

954 Grassland: Interactions Between Photodegradation and Litter Layer Thickness. Ecosystems, 11, 545-554

955 Hörtensteiner, S. (2006). CHLOROPHYLL DEGRADATION DURING SENESCENCE. Annual

956 Review of Plant Biology, 57, 55-77

957 Houborg, R., \& Anderson, M. (2009). Utility of an image-based canopy reflectance modeling tool for remote estimation of LAI and leaf chlorophyll content at regional scales. In (p. 29): SPIE

Houborg, R., Anderson, M., \& Daughtry, C. (2009). Utility of an image-based canopy reflectance modeling tool for remote estimation of LAI and leaf chlorophyll content at the field scale. Remote Sensing of Environment, 113, 259-274

962

963

964

965

966

967

968

969

970

971

972

973

974

975

976

977

978

979

980

981

982

983

984

985

Houborg, R., \& Boegh, E. (2008). Mapping leaf chlorophyll and leaf area index using inverse and forward canopy reflectance modeling and SPOT reflectance data. Remote Sensing of Environment, 112, 186-202

Houborg, R., McCabe, M., Cescatti, A., Gao, F., Schull, M., \& Gitelson, A. (2015). Joint leaf chlorophyll content and leaf area index retrieval from Landsat data using a regularized model inversion system (REGFLEC). Remote Sensing of Environment, 159, 203-221

Houborg, R., \& McCabe, M.F. (2016). Adapting a regularized canopy reflectance model (REGFLEC) for the retrieval challenges of dryland agricultural systems. Remote Sensing of Environment, 186, 105120

IPCC (2014). Climate Change 2014: Synthesis Report. Contribution of Working Groups I, II and III to the Fifth Assessment Report of the Intergovernmental Panel on Climate Change. In R.K.P.a.L.A. Meyer (Ed.) (p. 151). Geneva, Switzerland: IPCC

Jacquemoud, S. (1988). Modélisation des propriétés optiques des feuilles. In: USTL / ENSA Montpellier / INRA

Jacquemoud, S., \& Baret, F. (1990). PROSPECT: A model of leaf optical properties spectra. Remote Sensing of Environment, 34, 75-91

Jacquemoud, S., Verhoef, W., Baret, F., Bacour, C., Zarco-Tejada, P.J., Asner, G.P., François, C., \& Ustin, S.L. (2009). PROSPECT+SAIL models: A review of use for vegetation characterization. Remote Sensing of Environment, 113, S56-S66

Kidnie, S., Cruz, M.G., Gould, J., Nichols, D., Anderson, W., \& Bessell, R. (2015). Effects of curing on grassfires: I. Fuel dynamics in a senescing grassland. International Journal of Wildland Fire, 24, 828837

Koukoura, Z., Mamolos, A.P., \& Kalburtji, K.L. (2003). Decomposition of dominant plant species litter in a semi-arid grassland. Applied Soil Ecology, 23, 13-23 
bioRxiv preprint doi: https://doi.org/10.1101/2020.02.05.935064; this version posted February 6, 2020. The copyright holder for this preprint (which was not certified by peer review) is the author/funder, who has granted bioRxiv a license to display the preprint in perpetuity. It is made available under aCC-BY 4.0 International license.

986

987

988

989

990

991

992

993

994

995

996

997

998

999

1000

1001

1002

1003

1004

1005

1006

1007

1008

1009

1010

1011

1012

1013

1014

1015

1016

1017

1018

1019

1020

1021

1022

1023

Luo, Y., El-Madany, T., Filippa, G., Ma, X., Ahrens, B., Carrara, A., Gonzalez-Cascon, R., Cremonese, E., Galvagno, M., Hammer, T., Pacheco-Labrador, J., Martín, M., Moreno, G., Perez-Priego, O., Reichstein, M., Richardson, A., Römermann, C., \& Migliavacca, M. (2018). Using Near-InfraredEnabled Digital Repeat Photography to Track Structural and Physiological Phenology in Mediterranean Tree-Grass Ecosystems. Remote Sensing, 10, 1293

Martín, M.P., Pacheco-Labrador, J., Gonzalez-Cascon, R., Moreno, G., Migliavacca, M., García, M., Yebra, M., \& Riaño, D. (2019). Estimación de variables esenciales de la vegetación en un ecosistema de dehesa utilizando factores de reflectividad simulados con PROSAIL + FLIGHT. In A.E.d. Teledetección (Ed.), XVIII Congreso Nacional de Teledetección. Valladolid, Spain, 24-27 September 2019

Martini, D., Pacheco-Labrador, J., Perez-Priego, O., van der Tol, C., El-Madany, S.T., Julitta, T., Rossini, M., Reichstein, M., Christiansen, R., Rascher, U., Moreno, G., Martín, P.M., Yang, P., Carrara, A., Guan, J., González-Cascón, R., \& Migliavacca, M. (2019). Nitrogen and Phosphorus Effect on SunInduced Fluorescence and Gross Primary Productivity in Mediterranean Grassland. Remote Sensing, 11

McKay, M.D., Beckman, R.J., \& Conover, W.J. (1979). A Comparison of Three Methods for Selecting Values of Input Variables in the Analysis of Output from a Computer Code. Technometrics, 21, 239245

Melendo-Vega, J., Martín, M., Pacheco-Labrador, J., González-Cascón, R., Moreno, G., Pérez, F., Migliavacca, M., García, M., North, P., \& Riaño, D. (2018). Improving the Performance of 3-D Radiative Transfer Model FLIGHT to Simulate Optical Properties of a Tree-Grass Ecosystem. Remote Sensing, 10, 2061

Migliavacca, M., Galvagno, M., Cremonese, E., Rossini, M., Meroni, M., Sonnentag, O., Cogliati, S., Manca, G., Diotri, F., Busetto, L., Cescatti, A., Colombo, R., Fava, F., Morra di Cella, U., Pari, E., Siniscalco, C., \& Richardson, A.D. (2011). Using digital repeat photography and eddy covariance data to model grassland phenology and photosynthetic CO2 uptake. Agricultural and Forest Meteorology, $151,1325-1337$

Migliavacca, M., Perez-Priego, O., Rossini, M., El-Madany, T.S., Moreno, G., van der Tol, C., Rascher, U., Berninger, A., Bessenbacher, V., Burkart, A., Carrara, A., Fava, F., Guan, J.-H., Hammer, T.W., Henkel, K., Juarez-Alcalde, E., Julitta, T., Kolle, O., Martín, M.P., Musavi, T., Pacheco-Labrador, J., Pérez-Burgueño, A., Wutzler, T., Zaehle, S., \& Reichstein, M. (2017). Plant functional traits and canopy structure control the relationship between photosynthetic $\mathrm{CO} 2$ uptake and far-red sun-induced fluorescence in a Mediterranean grassland under different nutrient availability. New Phytologist, 214, 1078-1091

Omlin, M., \& Reichert, P. (1999). A comparison of techniques for the estimation of model prediction uncertainty. Ecological Modelling, 115, 45-59

Pacheco-Labrador, J., El-Madany, T., Martín, M., Migliavacca, M., Rossini, M., Carrara, A., \& ZarcoTejada, P.J. (2017). Spatio-Temporal Relationships between Optical Information and Carbon Fluxes in a Mediterranean Tree-Grass Ecosystem. Remote Sensing, 9, 608 
bioRxiv preprint doi: https://doi.org/10.1101/2020.02.05.935064; this version posted February 6, 2020. The copyright holder for this preprint (which was not certified by peer review) is the author/funder, who has granted bioRxiv a license to display the preprint in perpetuity. It is made available under aCC-BY 4.0 International license.

1024 Pacheco-Labrador, J., Perez-Priego, O., El-Madany, T.S., Julitta, T., Rossini, M., Guan, J., Moreno, G., 1025 Carvalhais, N., Martín, M.P., Gonzalez-Cascon, R., Kolle, O., Reischtein, M., van der Tol, C., Carrara, 1026 A., Martini, D., Hammer, T.W., Moossen, H., \& Migliavacca, M. (2019). Multiple-constraint inversion 1027 of SCOPE. Evaluating the potential of GPP and SIF for the retrieval of plant functional traits. Remote 1028 Sensing of Environment, 234, 111362

1029 Perez-Priego, O., El-Madany, T.S., Migliavacca, M., Kowalski, A.S., Jung, M., Carrara, A., Kolle, O., 1030 Martín, M.P., Pacheco-Labrador, J., Moreno, G., \& Reichstein, M. (2017). Evaluation of eddy 1031 covariance latent heat fluxes with independent lysimeter and sapflow estimates in a Mediterranean 1032 savannah ecosystem. Agricultural and Forest Meteorology, 236, 87-99

1033 Perez-Priego, O., Guan, J., Rossini, M., Fava, F., Wutzler, T., Moreno, G., Carvalhais, N., Carrara, A., 1034 Kolle, O., Julitta, T., Schrumpf, M., Reichstein, M., \& Migliavacca, M. (2015). Sun-induced 1035 chlorophyll fluorescence and photochemical reflectance index improve remote-sensing gross primary 1036 production estimates under varying nutrient availability in a typical Mediterranean savanna ecosystem. 1037 Biogeosciences, 12, 6351-6367

1038 Porcar-Castell, A., Tyystjärvi, E., Atherton, J., van der Tol, C., Flexas, J., Pfündel, E.E., Moreno, J., 1039 Frankenberg, C., \& Berry, J.A. (2014). Linking chlorophyll a fluorescence to photosynthesis for remote 1040 sensing applications: mechanisms and challenges. Journal of Experimental Botany, 65, 4065-4095

1041 Pourcel, L., Routaboul, J.-M., Cheynier, V., Lepiniec, L., \& Debeaujon, I. (2007). Flavonoid oxidation 1042 in plants: from biochemical properties to physiological functions. Trends in Plant Science, 12, 29-36

1043 Ren, H., \& Zhang, B. (2018). Spatiotemporal variations in litter mass and their relationships with 1044 climate in temperate grassland: A case study from Xilingol grassland, Inner Mongolia (China). 1045 Advances in Space Research, 61, 1055-1065

1046 Richardson, A.D., Keenan, T.F., Migliavacca, M., Ryu, Y., Sonnentag, O., \& Toomey, M. (2013). 1047 Climate change, phenology, and phenological control of vegetation feedbacks to the climate system. 1048 Agricultural and Forest Meteorology, 169, 156-173

1049 Rogers, A. (2014). The use and misuse of V c,max in Earth System Models. Photosynthesis Research, 1050 119, $15-29$

1051 Rogers, A., Medlyn Belinda, E., Dukes Jeffrey, S., Bonan, G., Caemmerer, S., Dietze Michael, C., 1052 Kattge, J., Leakey Andrew, D.B., Mercado Lina, M., Niinemets, Ü., Prentice, I.C., Serbin Shawn, P., 1053 Sitch, S., Way Danielle, A., \& Zaehle, S. (2016). A roadmap for improving the representation of 1054 photosynthesis in Earth system models. New Phytologist, 213, 22-42

1055 Rouse, J.W., Haas, R.H., Schell, J.A., \& Deering, D.W. (1974). Monitoring vegetation systems in the 1056 Great Plains with ERTS. In S.C. Freden, E.P. Mercanti, \& M.A. Becker (Eds.), Third Earth Resources 1057 Technology Satellite- 1 Symposium (pp. 301-317). Greenbelt, MD, USA: NASA

1058 Sanaullah, M., Chabbi, A., Lemaire, G., Charrier, X., \& Rumpel, C. (2010). How does plant leaf 1059 senescence of grassland species influence decomposition kinetics and litter compounds dynamics? 1060 Nutrient Cycling in Agroecosystems, 88, 159-171 
bioRxiv preprint doi: https://doi.org/10.1101/2020.02.05.935064; this version posted February 6, 2020. The copyright holder for this preprint (which was not certified by peer review) is the author/funder, who has granted bioRxiv a license to display the preprint in perpetuity. It is made available under aCC-BY 4.0 International license.

1061 Schaefer, K., Schwalm Christopher, R., Williams, C., Arain, M.A., Barr, A., Chen Jing, M., Davis 1062 Kenneth, J., Dimitrov, D., Hilton Timothy, W., Hollinger David, Y., Humphreys, E., Poulter, B., 1063 Raczka Brett, M., Richardson Andrew, D., Sahoo, A., Thornton, P., Vargas, R., Verbeeck, H., 1064 Anderson, R., Baker, I., Black, T.A., Bolstad, P., Chen, J., Curtis Peter, S., Desai Ankur, R., Dietze, M., 1065 Dragoni, D., Gough, C., Grant Robert, F., Gu, L., Jain, A., Kucharik, C., Law, B., Liu, S., Lokipitiya, 1066 E., Margolis Hank, A., Matamala, R., McCaughey, J.H., Monson, R., Munger, J.W., Oechel, W., Peng, 1067 C., Price David, T., Ricciuto, D., Riley William, J., Roulet, N., Tian, H., Tonitto, C., Torn, M., Weng, 1068 E., \& Zhou, X. (2012). A model-data comparison of gross primary productivity: Results from the North 1069 American Carbon Program site synthesis. Journal of Geophysical Research: Biogeosciences, 117

1070 Serbin, S.P., Singh, A., Desai, A.R., Dubois, S.G., Jablonski, A.D., Kingdon, C.C., Kruger, E.L., \& 1071 1072

1073 1074 1075

1076 1077 1078

1079 1080 1081

1082 1083 1084

1085 1086 1087

1088 1089

Townsend, P.A. (2015). Remotely estimating photosynthetic capacity, and its response to temperature, in vegetation canopies using imaging spectroscopy. Remote Sensing of Environment, 167, 78-87

Silva-Perez, V., Molero, G., Serbin, S.P., Condon, A.G., Reynolds, M.P., Furbank, R.T., \& Evans, J.R. (2018). Hyperspectral reflectance as a tool to measure biochemical and physiological traits in wheat. Journal of Experimental Botany, 69, 483-496

Sims, D.A., \& Gamon, J.A. (2002). Relationships between leaf pigment content and spectral reflectance across a wide range of species, leaf structures and developmental stages. Remote Sensing of Environment, 81, 337-354

Taranto, F., Pasqualone, A., Mangini, G., Tripodi, P., Miazzi, M.M., Pavan, S., \& Montemurro, C. (2017). Polyphenol Oxidases in Crops: Biochemical, Physiological and Genetic Aspects. International Journal of Molecular Sciences, 18, 377

van der Tol, C., Rossini, M., Cogliati, S., Verhoef, W., Colombo, R., Rascher, U., \& Mohammed, G. (2016). A model and measurement comparison of diurnal cycles of sun-induced chlorophyll fluorescence of crops. Remote Sensing of Environment, 186, 663-677

van der Tol, C., Verhoef, W., Timmermans, J., Verhoef, A., \& Su, Z. (2009). An integrated model of soil-canopy spectral radiances, photosynthesis, fluorescence, temperature and energy balance. Biogeosciences, 6, 3109-3129

Verhoef, W. (1984). Light scattering by leaf layers with application to canopy reflectance modeling: The SAIL model. Remote Sensing of Environment, 16, 125-141

Verhoef, W., \& Bach, H. (2003). Remote sensing data assimilation using coupled radiative transfer models. Physics and Chemistry of the Earth, Parts A/B/C, 28, 3-13

Verhoef, W., van der Tol, C., \& Middleton, E.M. (2018). Hyperspectral radiative transfer modeling to explore the combined retrieval of biophysical parameters and canopy fluorescence from FLEX Sentinel-3 tandem mission multi-sensor data. Remote Sensing of Environment, 204, 942-963

Vilfan, N., van der Tol, C., Muller, O., Rascher, U., \& Verhoef, W. (2016). Fluspect-B: A model for leaf fluorescence, reflectance and transmittance spectra. Remote Sensing of Environment, 186, 596-615 
bioRxiv preprint doi: https://doi.org/10.1101/2020.02.05.935064; this version posted February 6, 2020. The copyright holder for this preprint (which was not certified by peer review) is the author/funder, who has granted bioRxiv a license to display the preprint in perpetuity. It is made available under aCC-BY 4.0 International license.

1097 Vilfan, N., Van der Tol, C., Yang, P., Wyber, R., Malenovský, Z., Robinson, S.A., \& Verhoef, W. 1098 (2018). Extending Fluspect to simulate xanthophyll driven leaf reflectance dynamics. Remote Sensing of 1099 Environment, 211, 345-356

1100 Wang, Q., Tenhunen, J., Dinh, N.Q., Reichstein, M., Otieno, D., Granier, A., \& Pilegarrd, K. (2005). 1101 Evaluation of seasonal variation of MODIS derived leaf area index at two European deciduous 1102 broadleaf forest sites. Remote Sensing of Environment, 96, 475-484

1103 Wenhan, Q. (1993). Modeling bidirectional reflectance of multicomponent vegetation canopies. Remote 1104 Sensing of Environment, 46, 235-245

1105 Whitfield, D.M., \& Rowan, K.S. (1974). Changes in the chlorophylls and carotenoids of leaves of 1106 Nicotiana tabacum during senescence. Phytochemistry, 13, 77-83

1107 Yang, P., Verhoef, W., \& van der Tol, C. (2017). The mSCOPE model: A simple adaptation to the 1108 SCOPE model to describe reflectance, fluorescence and photosynthesis of vertically 1109 heterogeneous canopies. Remote Sensing of Environment, 201, 1-11

1110 Yuan, Z., \& Chen, H.Y.H. (2009). Global trends in senesced-leaf nitrogen and phosphorus. Global 1111 Ecology and Biogeography, 18, 532-542

1112 Zhang, Y., Guanter, L., Berry Joseph, A., Joiner, J., Tol, C., Huete, A., Gitelson, A., Voigt, M., \& 1113 Köhler, P. (2014). Estimation of vegetation photosynthetic capacity from space-based measurements of 1114 chlorophyll fluorescence for terrestrial biosphere models. Global Change Biology, 20, 3727-3742

1115 Zhang, Y., Guanter, L., Joiner, J., Song, L., \& Guan, K. (2018). Spatially-explicit monitoring of crop 1116 photosynthetic capacity through the use of space-based chlorophyll fluorescence data. Remote Sensing 1117 of Environment, 210, 362-374 